\title{
PREPARATION AND CHARACTERIZATION OF COMPOSITE MEMBRANE FOR HIGH TEMPERATURE GAS SEPARATION
}

Final Technical Report

Reporting Period: 09/01/1993 through 08/30/1997

Authors: Shamsuddin Ilias

Franklin G. King

Report Issue Date: 03/26/1998

DE-FG22-93MT93008 --17

North Carolina A\&T State University

Department of Chemical Engineering

Greensboro, NC 27411

Tel: (336) 334-7564

Fax: (336) 334-7904 


\section{DISCLAIMER}

This report was prepared as an account of work sponsored by an agency of the United States Government. Neither the United States Government nor any agency thereof, nor any of their employees, makes any warranty, express or implied, or assumes any legal liability or responsibility for the accuracy, completeness, or usefulness of any information, apparatus, product, or process disclosed, or represents that its use would not infringe privately owned rights. Reference herein to any specific commercial product, process, or service by trade name, trademark, manufacturer, or otherwise does not necessarily constitute or imply its endorsement, recommendation, or favoring by the United States Government or any agency thereof. The views and opinions of authors expressed herein do not necessarily state or reflect those of the United States Government or any agency thereof. 


\begin{abstract}
A new class of perm-selective inorganic membrane was developed by electroless deposition of palladium thin-film on a microporous $\alpha$-alumina ceramic substrate $(\phi 39 \mathrm{~mm} \times 2 \mathrm{~mm}$ thickness, nominal pore size $150 \mathrm{~nm}$ and open porosity $\approx 42 \%$ ). The new membrane was characterized by Scanning Electron Micrography (SEM), Energy Dispersive X-ray Analysis (EDX) and conducting permeability experiments with hydrogen, helium, argon and carbon dioxide at temperatures from 473 $\mathrm{K}$ to $673 \mathrm{~K}$ and feed pressures from $136 \mathrm{kPa}$ to $274 \mathrm{kPa}$. The results indicate that the membrane has both high permeability and selectivity for hydrogen. The hydrogen transport through the Pdcomposite membrane closely followed Sievert's law. A theoretical model is presented to describe the performance of a single-stage permeation process. The model uses a unified mathematical formulation and calculation methods for two flow patterns (cocurrent and countercurrent) with two permeable components and a nonpermeable fraction in the feed and a sweep stream in the permeate. The countercurrent flow pattern is always better than the cocurrent flow pattern with respect to stage cut and membrane area. The effect of flow configuration decreases with increasing membrane selectivity or with decreasing permeate/feed ratio.
\end{abstract}




\section{TABLE OF CONTENTS}

Title Page

$\begin{array}{ll}\text { Disclaimer } & \text { ii }\end{array}$

$\begin{array}{ll}\text { Abstract } & \text { iii }\end{array}$

Table of Contents

List of Tables $\quad$ V

List of Figures $\quad$ vi

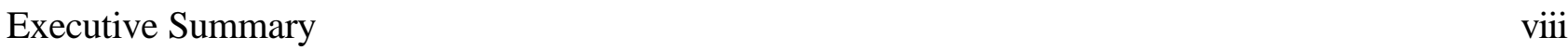

$\begin{array}{ll}\text { Introduction } & 1\end{array}$

$\begin{array}{ll}\text { Experimental Methods } & 4\end{array}$

$\begin{array}{ll}\text { Mathematical Model } & 8\end{array}$

$\begin{array}{ll}\text { Results and Discussions } & 13\end{array}$

$\begin{array}{lr}\text { Conclusions } & 18\end{array}$

$\begin{array}{lr}\text { Acknowledgments } & 19\end{array}$

$\begin{array}{ll}\text { Nomenclature } & 20\end{array}$

$\begin{array}{ll}\text { References } & 22\end{array}$ 


\section{LIST OF TABLES}

TABLE 1: $\quad$ Typical Electroless Plating Bath Composition 24

TABLE 2: Composition of Sensitization and Activation Solutions $\quad 24$

TABLE 3: Summary of Hydrogen Permeability Data at Specific 25

Temperatures for Palladium-Ceramic Composite Membranes.

TABLE 4: $\quad$ Computed Hydrogen Permeability Using $P_{H}=P_{H o} \exp \frac{E_{H}}{R T}$

at Indicated Temperatures for New Palladium-Ceramic

Composite Membranes. 


\section{LIST OF FIGURES}

FIGURE 1: Schematic of permeability measurement setup 26

$\begin{array}{ll}\text { FIGURE 2: } & \text { Details of diffusion cell }\end{array}$

FIGURE 3: Schematic diagrams of flow configurations in single-stage 28 permeation cell: (a) cocurrent, and (b) countercurrent

FIGURE 4: Energy Dispersive X-ray (EDX) analysis of electroless deposited palladium film on ceramic substrate

FIGURE 5: $\quad$ SEM micrographs of Pd-ceramic composite membrane:

(a) sample specimen, (b) SEM of substrate, (c) SEM of sensitized

(b) and activated substrate surface, and (d) SEM of electroless

(c) deposited Pd-film on ceramic substrate

FIGURE 6: $\quad$ Effect of driving force, $\left[\boldsymbol{p}_{H} \mathbf{q}-\mathfrak{p}_{H} \mathbf{g}\right]$ on hydrogen permeation

fluxes at various temperatures through the palladium-ceramic composite membrane with a film thickness of $8 \mu \mathrm{m}$ and $n=0.778$.

FIGURE 7: $\quad$ Effect of driving force, $\left[b_{H},-b_{H} \mathbf{g}\right]$ on hydrogen permeation

fluxes at various temperatures through the palladium-ceramic composite membrane with a film thickness of $8 \mu \mathrm{m}$ and $n=0.501$.

FIGURE 8: Effect of temperature on hydrogen permeability through palladium-ceramic composite membranes.

FIGURE 9: $\quad$ Effect of driving force, $\left[p_{H} 9-b_{H}\right)$ on hydrogen permeation fluxes at various temperatures through the palladium-ceramic composite membrane with a film thickness of $9.77 \mu \mathrm{m}$ and $n=0.513$.

FIGURE 10: Effect of driving force, $\left[\boldsymbol{p}_{H_{e}} \mathbf{q}-\boldsymbol{p}_{\mathrm{He}} \mathbf{g}\right]$ on helium permeation

fluxes at various temperatures through the palladium-ceramic composite membrane with a film thickness of $9.77 \mu \mathrm{m}$ and $n=1.1$

FIGURE 11: Effect of driving force, $\left[p_{H} \mathbf{9}-p_{H} \mathbf{9}\right.$ on hydrogen permeation

fluxes at various temperatures through the palladium-ceramic composite membrane with a film thickness of $9.77 \mu \mathrm{m}$ and $n=0.623$ for $\mathrm{N}_{2} / \mathrm{H}_{2}$ mixture. 
FIGURE 12: Effect of driving force, $\left[\boldsymbol{p}_{H} 9-b_{H} 9\right]$ on hydrogen permeation

fluxes at various temperatures through the palladium-ceramic composite membrane with a film thickness of $9.77 \mu \mathrm{m}$ and $n=0.564$ for $\mathrm{CH}_{4} / \mathrm{H}_{2}$ mixture.

FIGURE 13: Effect of transmembrane pressure difference $\left[p_{H} 9-p_{H} g\right]$ on hydrogen/carbon dioxide selectivity at various temperatures for palladium-ceramic composite membrane with $9.77 \mu$ mpalladium film for pure gases.

FIGURE 14: Effect of transmembrane pressure difference $\left[p_{H} 9-p_{H} g\right.$ on hydrogen/argon selectivity at various temperatures for palladium-ceramic composite membrane with $9.77 \mu \mathrm{m}$ palladium film for pure gases.

FIGURE 15: Effect of transmembrane pressure difference $\left[b_{H} 9-p_{H} g\right.$ on hydrogen/argon selectivity at various temperatures for palladium-ceramic composite membrane with $9.77 \mu$ m palladium film for pure gases.

FIGURE 16: Effect of transmembrane pressure difference $\left[p_{H} g-p_{H} g\right]$ on hydrogen/argon selectivity at various temperatures for hydrogen selective ceramic membrane (commercial) for pure gases.

FIGURE 17: Effect of transmembrane pressure difference $\left[p_{H} 9-p_{H} g\right.$ on hydrogen/carbon dioxide selectivity at various temperatures for hydrogen selective ceramic membrane (commercial) for pure gases.

FIGURE 18: Effect of transmembrane pressure difference $\left[p_{H} 9-p_{H} g\right.$ on hydrogen/argon selectivity at various temperatures for hydrogen selective ceramic membrane (commercial) for pure gases.

FIGURE 19: Effect of pressure ratio on permeate and reject compositions at $573 \mathrm{~K}$ compared to model predictions for palladium-ceramic composite membrane with $9.77 \mu \mathrm{m}$ film for cocurrent flow model.

FIGURE 20: Effect of pressure ratio on permeate and reject compositions at $573 \mathrm{~K}$ compared to model predictions for palladium-ceramic composite membrane with $9.77 \mu \mathrm{m}$ film for countercurrent flow model. 


\section{EXECUTIVE SUMMARY}

The development of high temperature membranes to recover hydrogen is a topic of considerable scientific interest. Coal gasification and several other high-temperature industrial processes generate hydrogen as a byproduct. These processes offer potentially significant source of hydrogen for use in clean power generation (e.g., fuel calls) and as primary chemical feedstock. Recently, there has been increased interest in developing inorganic and composite membranes for in-situ separation of hydrogen to achieve equilibrium shift in a catalytic reactor. To develop a new class of hydrogen permselective inorganic membrane, electroless plating was used to deposit a thin palladium film on a microporous ceramic substrate. The palladium film on the microporous ceramic substrate acts as selective separation barrier for hydrogen separation. This palladium-ceramic composite membrane was tested and characterized for hydrogen separation. From permeability studies with pure gases and pairs of mixed gases, it was found that the new membrane has a very high permselectivity for hydrogen and permeability increases with increasing operating temperature. Thus, the membrane has potential for applications at elevated temperature for hydrogen separation and also for use in membrane reactors for production and separation of hydrogen from dehydrogenation reactions. A theoretical model is presented to describe the performance of a single-stage permeation process. 


\section{INTRODUCTION}

\section{INTRODUCTION}

Membranes are primarily used for selective separation of a component from a mixture. Major membrane processes include gas separation, reverse osmosis, ultrafiltration, microfiltration and pervaporation. Large-scale commercial uses of membrane separations have displaced conventional separation processes. Membrane separation systems offer significant advantages over existing separation processes. Membrane processes consume less energy than conventional processes. They are also compact and modular and are easy to retrofit to existing industrial processes. Over the last 30 years, such processes have been widely accepted in the chemical and petrochemical refining industries. Examples of the application for membrane gas separation are the removal of hydrogen from purge gases, the separation of hydrogen and carbon monoxide in synthesis gas, oxygen and nitrogen separation from air, dehumidification of gas streams and the recovery of high purity hydrogen. Other applications are separation of hydrogen sulfide from methane and recovery of carbon dioxide from the miscible flooding in the petroleum [1]. The potential application of membranes in high temperature gas separation and reactor technology has been recognized by many investigators [2-7].

In recent years, the use of membranes in reaction engineering has been recognized [8-12]. By selectively separating the products from the reaction mixture, it is possible to achieve significant enhancement over equilibrium conversion. Shifting the thermodynamic equilibrium in this manner has obvious industrial interest. It allows for reduced reaction temperatures, thereby minimizing side reactions and heating costs. Also, reaction and separation can be achieved in a single unit, making the membrane reactor a cost-effective unit operation.

The advantages of membrane gas separation has promoted the search for more durable membranes. Such durable membranes could be used under extreme temperatures where currently used polymer membranes are not suitable because of their thermal instability. Some composite polymeric membranes can be used up to $473 \mathrm{~K}$. However, for many industrially important gas-phase reactions the operating temperatures are much higher than $473 \mathrm{~K}$ [1]. For example, dehydrogenation of cyclohexane to synthesize benzene, coal gassification, water gas shift reaction, Claus process of sulfur generation from hydrogen sulfide, etc. operate at elevated temperatures and pressures. If a 
membrane gas separation processes is integrated into traditional chemical processes because of its high temperature resistance, the process will become energy efficient. This kind of breakthrough will definitely add a new dimension to the applications of membrane technology.

Polymer membranes have thermal instability. Inorganic membranes (mostly ceramic) although thermally stable, lack permselectivity because of their porous nature. A major challenge lies in developing a permselective thin solid film with structured integrity and desired properties. However, very thin membranes may have the drawback of a low mechanical strength. One way to overcome this difficulty is to make composite membranes consisting of a thin membrane deposited on a thermally stable porous substrate. The composite structure will act as a membrane with high selectivity and high flux.

Commercially available non-porous membranes for hydrogen separation at high temperatures are either thick film or thick walled tubes. Since permeability is inversely proportional to film thickness, a thick film membrane acts as a poor perm-separator. The productivity of these membranes in a membrane reactor-separator is severely limited by the poor permeability of the membranes. Thus, a major challenge lies in developing a perm-selective thin film without compromising the integrity of the film. The success of membranes in these applications will largely depend on the availability of membranes with acceptable perm-selectivity and thermal stability [13]. The availability of such a membrane for high temperature application could open new areas of research in membrane reactor technology and gas separation.

\section{RESEARCH OBJECTIVES}

The primary objective of this study is to prepare and characterize a composite Pd-ceramic membrane suitable for high temperature gas separation and catalytic membrane reactors. The major objectives can be divided into the development of a method for composite membrane formation and the characterization of fabricated composite membrane. To develop a new class of hydrogen permselective membrane, we used electroless plating to deposit palladium thin-film on microporous ceramic substrate. The major parts of this research can be divided into following three sections:

a. Preparation \& characterization of palladium-ceramic composite membrane; 
b. Evaluation of hydrogen perm-selectivity of the new membrane;

c. Development of theoretical models to study the performance of single-stage membrane module under cocurrent and countercurrent flow configuration.

This report summarizes the work performed under DOE Grant No. DE-FG22-93MT93008, covering the period $09 / 01 / 93$ to $08 / 30 / 97$. 


\section{EXPERIMENTAL METHODS}

The development of a process for producing ultra thin-film, defect-free composite membranes is important. If such a process is to be developed in a generally applicable form for use with most advanced materials, a high-productivity, high-selectivity coating must be applied on an inexpensive support. To develop a novel permselective inorganic membranes, we have used electroless plating to deposit a palladium thin-film on a microporous ceramic substrate [14]. Electroless plating is a controlled, autocatalytic deposition of a continuous film on the surface of a substrate by the interaction of a metal salt and a chemical reducing agent. The electroless plating method can deposit thin films of metals, alloys and composites on both conducting and nonconducting surfaces. Three types of experiments were performed: electroless plating of palladium on a ceramic substrate, characterization of palladium thin-film composite membranes, and evaluation of the perm-selectivity of the composite membrane for hydrogen separation.

\section{Electroless Plating of Ceramic Substrate}

Microporous ceramic alumina membranes (a-alumina, ф $39 \mathrm{~mm} \times 2 \mathrm{~mm}$ thickness, nominal pore size $150 \mathrm{~nm}$ and open porosity . 42\% obtained from Velterop Ceramic Membrane Company of the Netherlands) were coated with a thin palladium film by electroless plating. Electroless plating is a combination of the cathodic deposition of metal and the anodic oxidation of reductant at the immersion potential $[14,15]$. Palladium deposition occurs as the result of the following simultaneous reactions:

Anodic Reaction:

$$
\mathrm{N}_{2} \mathrm{H}_{4}+4 \mathrm{OH}^{-1} \rightarrow \mathrm{N}_{2}+4 \mathrm{H}_{2} \mathrm{O}+4 \mathrm{e}^{-}
$$

Cathodic Reaction:

$$
2 \mathrm{Pd}\left[\mathrm{NH}_{3}\right]_{4}^{2+}+4 \mathrm{e}^{-} \rightarrow 2 \mathrm{Pd}^{0}+8 \mathrm{NH}_{3}
$$

\section{Autocatalytic Reaction:}

$$
2 \mathrm{Pd}\left[\mathrm{NH}_{3}\right]_{4}^{2+}+\mathrm{N}_{2} \mathrm{H}_{4}+4 \mathrm{OH}^{-} \rightarrow 2 \mathrm{Pd}^{0}+\mathrm{N}_{2}+4 \mathrm{H}_{2} \mathrm{O}+8 \mathrm{NH}_{3}
$$

Electroless plating is a three-step process involving pretreatment of the substrate, sensitization 
and activation of the substrate surface, and electroless plating. The electroless plating bath compositions used are given in Table 1. The plating bath compositions are similar to ones used by others $[17,18]$.

In electroless plating, pretreatment of the substrate is an essential first step in order to deposit metals effectively. One of the common procedures is the two-step immersion sequence using an acidic stannous chloride solution followed by an acidic palladium salt solution. The first bath is referred to as the sensitizer (stannous chloride solution), while the second bath is referred as the activator (palladium salt solution). The net result of the pretreatment sequence is the formation of finelydivided palladium nuclei which initiate the autocatalytic plating process. The formation of the palladium metal nuclei is believed to be due to a redox reaction taking place between the adsorbed or absorbed stannous ions on the surface and the palladium ions in the activation solution. The sensitization and activation step can be described by the following reaction:

$$
\mathrm{Sn}^{2+}+\mathrm{Pd}^{2+} \rightarrow \mathrm{Sn}^{4+}+\mathrm{Pd}^{0}
$$

The sensitization process controls whether the final metallic film is uniform. The composition of the sensitization and activation solutions is given in Table 2. The procedure used for electroless plating of palladium on ceramic substrate may be summarized as follows:

\section{Pretreatment of the Substrate:}

The ceramic disks were cleaned by boiling in $0.1 \mathrm{~N} \mathrm{NaOH}$ solution for 10 to 30 minutes and then boiling in $0.1 \mathrm{~N} \mathrm{HCl}$ solution for 10 minutes. The cleaning was done to remove any organisms, residual metals and dust. The disks were then washed in boiled distilled water for 10 minutes, dried at $120^{\circ} \mathrm{C}$ and weighed. The cleaning was essential for activation and plating to take place across the diameter and into the porous substrate.

\section{Sensitization and Activation:}

One face and the edges of the pretreated ceramic disk was wrapped with Teflon tape to prevent sensitization and activation. The ceramic substrate was seeded with palladium by being dipped successively in acidic $\mathrm{SnCl}_{2}$ solution followed by acidic $\mathrm{PdCl}_{2}$ solution at room temperature. Each dip lasted for about 4 to 5 minutes and was followed by washing with distilled water for about one minute between each dip. The sensitization and activation step took about 0.5 to 1 hour. After sensitization and activation, the disks appeared grayish brown. The discs were dried at $120^{\circ} \mathrm{C}$ for 
1 hour and then weighed.

\section{Electroless Plating:}

The activated discs were wrapped with fresh tape and then suspended in temperature controlled electroless plating. The bath was preheated to the plating temperature. The total plating time was 0.5 hour for each run. The plated disc was then dried at $120^{\circ} \mathrm{C}$ for 1 hour and then weighed. For thicker film, it was necessary to use fresh electroless plating solution. For recoating the same surface, the Teflon tape needed to be replaced with new tape.

\section{Membrane Characterization}

The membranes were evaluated by taking SEM (Scanning Electron Microscope) micrographs, performing EDX (Energy-Dispersive X-ray) analysis and measuring the thickness of the coated film. EDX analysis was used to determine the composition of the plated membrane. The thickness of the palladium film was determined by a weight gain method. Membrane surface structure was evaluated from the SEM micrographs.

\section{Permeability Studies}

A steady-state counter-diffusion method, using gas chromatographic analysis, was used to measure the permeability and selectivity of the composite palladium membrane for hydrogen separation. The method consists of a diffusion cell designed to allow permeation of two different gases through a membrane or porous sample. Details of the method and calculation of permeability have been presented elsewhere [14]. The membranes were evaluated for hydrogen separation by conducting permeability measurements with hydrogen and argon at various temperatures and transmembrane pressure differentials.

The permeability testing assembly consisted of two pure gas sources, a diffusion cell, a tubular furnace, rotameters and massflow meters. The composite membrane was mounted in the center of cell. The diffusion cell was assembled and placed in a tubular furnace (Lindberg Type 55347). Each side of the cell was connected to a gas supply line. All inlet and outlet gas supply lines were constructed of stainless steel tubing. The temperature was controlled by a temperature controller. The pressure of the gas streams were measured by pressure gauges and regulated using valves as well as a pressure transducer. Calibrated rotameters and massflow meters were used to measure the flow rates of each of the inlet and exit gas streams. A differential pressure gauge was connected to 
each side of the cell to measure the differential pressure across the membrane. The composition of each exit gas was determined by manual sampling, using a syringe, and injected the sample in the Gas Chromatograph. A schematic of the experimental setup is shown in Figure 1.

During the early phase of this work, a stainless-steel diffusion cell was used to measure the permeability and diffusivity of hydrogen through the ceramic substrate and Pd-composite membrane. At elevated temperature, the leakage of hydrogen through the seals was a serious problem. To overcome the hydrogen leakage problem, we obtained and tested a new cell (designed by Velterop Ceramic Membrane Company of the Netherlands, Model LTC Type K-500). The new cell was selected because it is self-sealing at high temperature. The cell consisted of outer parts, inner parts, graphite seals, Copper-seals and the membrane is mounted on nonporous endseals. The details of the diffusion cell is shown in Figure 2.

The outer parts of the cell are made of stainless steel, AISI 310 and the inner parts are made of titanium. The outer diameter of the cell housing is $86 \mathrm{~mm}$ and the thickness of the housing is 37 $\mathrm{mm}$. The cell accepts ceramic disks, $\phi 39 \mathrm{~mm} \times 2 \mathrm{~mm}$, with ceramic sealing edge $\phi 60 \mathrm{~mm} \times 35 \mathrm{~mm}$. The effective surface area for diffusion is $12 \mathrm{~cm}^{2}$. The cell assembly can be used up to $120^{\circ} \mathrm{C}$. The thermal expansions of the two metals are such that the cell is selfsealing at elevated temperature. Graphite seals were used for sealing the ceramic edge and the copper-seals were used for connecting tubes. The result was very satisfactory. No external leakage of hydrogen was detected at operating pressures by the bubble test method. The ease of assembly of the cell also makes it convenient to use the membrane in repetitive applications without damaging the cell or membrane assembly.

A Perkin-Elmer Sigma 2000 Gas Chromatograph (GC), which was connected with a PerkinElmer 7700 computer and Perkin-Elmer LCI-100 Computing Integrator, was used to analyze the composition of the exit gas streams. A $15 \mathrm{ft}$ long, 1/8" OD Carboxon ${ }^{\mathrm{TM}} 1000$ column (Supleco, Inc.) connected to thermal conductivity detector (TCD), was used for gas separation in the GC. Helium was used as the carrier gas in all GC analyses. 


\section{MATHEMATICAL MODEL}

The permeation of hydrogen through a palladium film is a complex process consisting of multiple steps. The process begins with sorption of hydrogen molecules on the film surface and ends with hydrogen desorption from the ceramic substrate. It is believed that the hydrogen molecule dissociates into hydrogen atoms on one side of the film. The hydrogen atoms then diffuse through the film and reassociate on the other side. Since the reaction kinetics for the formation of hydrogen atoms from molecules and the reverse reaction are assumed to be very fast, the permeation of the hydrogen atoms through the film is the rate limiting step. Permeability can be considered as product of solubility and diffusivity. The permeation rate of hydrogen can be given by [20]:

$$
J_{a}=\frac{Q_{a}}{h}\left[\boldsymbol{B}_{x_{a}} \mathbf{9}-\boldsymbol{D}_{a} \mathbf{9}\right.
$$

If diffusion through the bulk metal is the rate limiting step and hydrogen atoms form an ideal solution in the metal, then Sievert's law holds for hydrogen solubility dependence and $n$ is equal to 0.5. The hydrogen flux is inversely proportional to the palladium film thickness $\mathbf{D}$ when the bulk diffusion is the rate limiting step. For polymeric membrane, where selective transport of a gas is by a solutiondiffusion process, the index $n$ is 1 . For thin-film palladium-ceramic composite membrane, $n$ lies between 0.5 to 1 .

The design of a membrane module requires a detailed analysis of the flow patterns for gas separations using Eqn. (1). A unified model was formulated to study the effect of membrane dependent index $n$, varying from 0.5 to 1 for cocurrent and countercurrent flow configurations with two permeable components and a non-permeable fraction in the feed and a sweep stream in the permeate.

\section{Formulation of A COCURRent Flow MODEL}

Figure 3(a) illustrates a cocurrent flow pattern for a membrane-based gas permeator with plug flow on each side of the membrane. The model is based on a three component gas mixture with components $a$ (more permeable), $b$ (less permeable) and $i$ (non-permeable). By considering a differential area element $d S$, the following permeation rate equations can be obtained for the permeable gas components: 


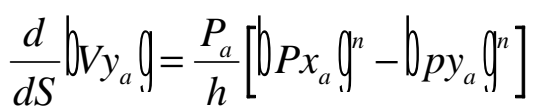

$$
\begin{aligned}
& \frac{d}{d s} \boldsymbol{b}_{i} \mathbf{g}{ }_{h}^{P_{h}}\left[\boldsymbol{b}_{i} \mathbf{g} \mid \boldsymbol{b}_{i} \mathbf{g}\right.
\end{aligned}
$$

If we define the membrane permeability ratio as selectivity, $\alpha=\frac{P_{a}}{P_{b}}$, and the ratio of pressures as $\gamma$, $\gamma=\frac{P}{p}$, Eqns. (2) and (3) are then expressed as:

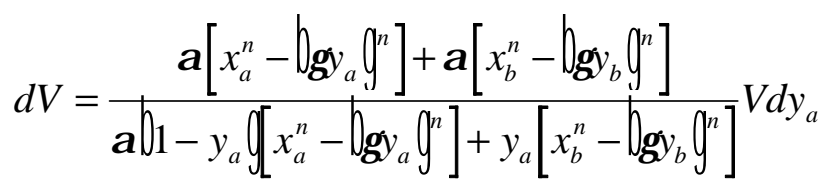

From a material balance of component $a$ about differential area $d S$, the differential local permeate flow rate may be expressed as:

$$
d V=\frac{L d x_{a}+V d y_{a}}{x_{a}-y_{a}}
$$

The overall component material balances between the inlet and an arbitrary point along the membrane for more permeable and non-permeable components are given by:

$$
\begin{aligned}
& L_{f}+V_{s}=L+V \\
& L_{f} x_{a f}+V_{s} y_{a s}=L x_{a}+V y_{a} \\
& L x_{i}=L_{f} x_{i f} \\
& V y_{i}=V_{s} y_{i s}
\end{aligned}
$$

If we define the ratio of the feed gas to sweep gas flow rates as $F_{f}$, and let $A=x_{a}^{n}-\bigotimes_{a}$ and $B=x_{b}^{n}-\bigotimes_{b}$, Eqns. (4) to (6) can be combined to give the following differential equation which relates changes in $y_{a}$ with $x_{a}$ :

$$
\frac{d y_{a}}{d x_{a}}=\frac{y_{a}-x_{a f}+F_{f} \mathbf{Q}_{a}-y_{a s} \mathbf{9} \alpha A \text { - } y_{a} \mathbf{Q} B y_{a}}{x_{a}-x_{a f}+F_{f}}
$$

The dimensionless membrane area can be related to the actual membrane area using the following expression in differential form:

$$
\frac{d R}{d S}=\frac{Q_{a} P^{n}}{h L_{f}}
$$


Combining Eqns. (3), (5), (7) and (8), the differential equation that relates the changes in $R$ with $x_{a}$ can be obtained as:

$$
\frac{d R}{d x_{a}}=\frac{\alpha\left[y_{a}-x_{a f}+F_{f} Q_{a}-y_{a s} \Phi\right.}{y_{a}}
$$

The solution of Eqns. (7) and (9) is an initial-value problem with the following initial conditions:

$$
\begin{array}{ll}
\text { at } R=0 ; & L=L_{f}, \quad x_{a}=x_{a f} \text { and } x_{i}=x_{i f} \\
\text { at } R=0 ; & V=V_{s}, \quad y_{a}=y_{a s} \text { and } y_{i}=y_{i s}
\end{array}
$$

Using Eqn. (9) and the mass balance equations, the local flowrate and non-permeable component composition on each side of the membrane can be computed using the following equations:

$$
\begin{aligned}
& L=\frac{y_{a}-x_{a f}+F_{f} \mathbf{Q}_{a}-y_{a s} \mathbf{Q}}{y_{a}-x_{a}} \\
& V=\frac{x_{a f}-x_{a}+F_{f} \widehat{Q}_{a s}-x_{a} \mathbf{O}}{y_{a}-x_{a}} \\
& x_{i}=\frac{L_{f} x_{i f}}{L}=\frac{x_{i f} \mathbf{Q}_{a}-x_{a} \mathbf{Q}}{y_{a}-x_{a f}+F_{f}}-y_{a s} \mathbf{O} \\
& y_{i}=\frac{V_{s} y_{i s}}{V}=\frac{y_{i s} F_{f} \mathbf{Q}_{a}-x_{a} \mathbf{9}}{x_{a f}-x_{a}+F_{f} \mathbf{Q}_{a s}-x_{a} \mathbf{9}}
\end{aligned}
$$

For the special case of no sweep gas on permeate side, the composition of component $a$ in the permeate side, $y_{a s}$, cannot be specified and must be determined from the permeate rate equations, Eqns. (2) and (3), with initial conditions, Eqn. (10), where $V_{s}=0$, and $y_{s}=0$. At the feedinlet point, $y_{a s}$ can be expressed as:

$$
\frac{y_{a s}}{1-y_{a s}}=\alpha \frac{x_{a f}^{n}-\bigotimes_{a s}}{x_{b f}^{n}-\bigotimes_{b s}}
$$

Thus, $y_{a s}$ may be solved from Eqn. (12) in terms of the feed conditions. It must be noted that Eqn. (7) appears to be indeterminate at the feed inlet because $V_{s}=0$, and $x_{a}=x_{a f}$. L'Hopital's rule, however, can be used to determine the derivative ${ }_{a}^{a_{a}} K_{f}$, the integration of Eqn. (7) may be carried out. 


\section{Formulation OF A COUNTERCURRENT Flow MODEL}

The countercurrent flow pattern is shown schematically in Figure 3(b). For this case, the feed gas and sweep gas flow in opposite directions. In this model, the material balances are taken between the reject end and any point along the membrane. For this case, $\mathrm{L}$ and $\mathrm{V}$ have opposite mathematical signs. The feed flow direction was arbitrarily selected to be positive. The differential equations that relate changes in $y_{a}$ and $R$ with $x_{a}$ can be expressed as:

$$
\begin{aligned}
& \frac{d y_{a}}{d x_{a}}=\frac{y_{a}-x_{a o}+F_{o} Q_{a}-y_{a s} \mathbf{g} \alpha A \text { D } y_{a} \mathbf{Q} B y_{a}}{x_{a}-x_{a o}+F_{o}}
\end{aligned}
$$

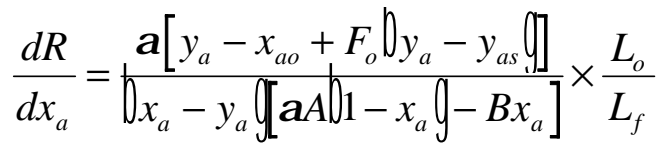

where $F_{o}$ is defined as the ratio of sweep gas to feed gas flow rates. Defining $R_{o}$ as the total dimensionless area, the boundary conditions are given as:

$$
\begin{aligned}
& \text { at } R=0 ; \quad L=L_{f}, \quad x_{a}=x_{a f} \text { and } \quad x_{i}=x_{i f} \\
& \text { at } R=R_{o} ; \quad V=V_{s}, \quad y_{a}=y_{a s} \quad \text { and } \quad y_{i}=y_{i s}
\end{aligned}
$$

Following the analysis of cocurrent flow pattern model, the local flowrates and nonpermeable component compositions on both sides of the membrane for countercurrent flow pattern can be calculated by the following equations:

$$
\begin{aligned}
& L=\frac{y_{a}-x_{a o}+F_{o} \mathbf{Q}-y_{a s} \mathbf{Q}}{y_{a}-x_{a}} \\
& V=\frac{x_{a o}-x_{a}+F_{o} \mathbf{Q}_{a}-x_{a} \mathbf{i}}{y_{a}-x_{a}} L_{o} \\
& x_{i}=\frac{L_{o} x_{i o}}{L}=\frac{x_{i o} \mathbf{Q}_{a}-x_{a} \mathbf{9}}{y_{a}-x_{a o}+F_{o}-y_{a s} \mathbf{9}} \\
& y_{i}=\frac{V_{s} y_{i s}}{V}=\frac{y_{i s} F_{o} \mathbf{Q}_{a}-x_{a} \mathbf{9}}{x_{a o}-x_{a}+F_{o}} \mathbf{Q}_{a s}-x_{a} \mathbf{g}
\end{aligned}
$$

For the special case of no sweep gas on permeate side, the composition of component $a$ in the permeate side, $y_{a s}$ cannot be specified and is related to the reject state. Similar to Eqn.(12), at the 
reject point, $y_{a s}$ can be expressed as:

$$
\frac{y_{a s}}{1-y_{a s}}=\alpha \frac{x_{a o}^{n}-\bigotimes_{a s} \mathbf{9}}{x_{b o}^{n}-\bigotimes_{b s} \mathbf{9}}
$$

Thus, $y_{a s}$ may be solved from Eqn. (17) in terms of reject conditions. It is to be noted that Eqn. (14) will appear to be indeterminate at the reject state because $V_{s}=0$, and $y_{a}=y_{a s}$. L'Hopital's rule,

however, can be used to determine the derivative, , the integration of Eqn. (14) may be carried out. The method of calculation is the same as the corresponding case with purging, but it is better to start the integration of Eqn. (14) from the reject end using the initial value of

\section{Solution Methodology}

The typical calculation problem is to determine the states of the permeate and reject streams and the membrane area requirement for a given feed and sweep gases conditions. When the flowrates $\boldsymbol{Q}_{f}$ and $V_{s} \overline{\mathbf{I}}$ and compositions $\mathbf{Q}_{s}, x_{i f}, y_{a s}$, and $y_{i s} \overline{\mathbf{I}}$ of feed and sweep gases and specified parameters $D_{\alpha}$, and $\gamma($ are given, there are seven unknown variables at the reject and permeate ends to be determined by six equations (Eqns. 7, 9 and 11 for cocurrent model and Eqns. 14, 15 and 16 for countercurrent model). Therefore, one of these variables can be freely chosen for parametric study.

In this work, the differential equations (Eqns. 7 and 9 for cocurrent flow and Eqns. 13 and 14 for countercurrent flow) were solved by the Runge-Kutta-Gill method. The coccurrent flow pattern problem was solved as an initial value problem, while the countercurrent flow problem was solved as a boundary value problem. The details of the solution methodology are given elsewhere [21]. 


\section{RESULTS AND DISCUSSIONS}

Thin-film palladium-ceramic composite membrane was developed by electroless deposition of palladium onto a planar ceramic substrate. Three Pd-ceramic composite membranes were fabricated and tested for hydrogen separation at high temperatures. The membranes were characterized by SEM and EDX analysis. The EDX analysis of the membrane specimen is shown in Figure 4. The analysis showed that the palladium film deposited on the ceramic substrate is essentially pure but contains a small amount of carbon in the plating. We are not sure about the source of carbon contamination in the palladium film.

Figure 5(a) shows a schematic of the composite membrane showing the location of palladium film and palladium activated seed on one side of the cleaned microporous ceramic substrate. Figures 5(b), 5(c) and 5(d) show the SEM micrographs of the ceramic substrate, sensitized and activated substrate (palladium seed) and the electroless deposited palladium film. Based on SEM micrographs, no significant surface modifications were observed after the substrate was activated and sensitized. The pore size remained more or less the same. However, the surface structure changed dramatically after the thin film was plated. All pores were fully covered by the solid palladium film and no pin holes were detected.

There is no universally accepted method for measuring the thickness of metallic coatings [19]. Weight-gain, differential thickness and SEM methods are considered most common. In this work, the film thickness was measured by the weight-gain method. In this method, the weight difference between the unplated and plated disc is divided by product of the disc surface area and the palladium density to obtain the approximate film thickness. We also measured the film thickness from differential thickness measurements using an Alpha-step 200 Scanning Profilometer. To apply this method, we masked part of the disk surface to create layers similar to the schematic shown in Figure 5a. Profilometer scanning of a sample membrane from the Pd-film surface to the seed surface and from the seed surface to the substrate were used to measure the differential thickness of palladium film deposit. The Pd-film thickness was found to be $0.83 \mu \mathrm{m}$ by this method. By the weight-gain method, the film thickness was estimated to be $8.5 \mu \mathrm{m}$. One explanation for the difference may be attributed to the so-called "plug-layer" phenomena. In the scanning method, one assumption was that no palladium was seeded in the pores of the substrate and the interface between the Pd-film and the substrate was flat. In reality, however, palladium could fill the pores of the substrate and the 
profilometer scans only the upper face of the film, while the actual film thickness could be much higher.

Three Pd-ceramic composite membrane specimens were fabricated by electroless deposition method as discussed earlier. The palladium film thicknesses were estimated by the weight-gain method to be $8.5,9.77$, and $12 \mu \mathrm{m}$. The permeability experiments were conducted on each specimen at temperatures of 373,473 and $673 \mathrm{~K}$. The pressure on the high pressure side (hydrogen) ranged from 170 to $240 \mathrm{kPa}$ and the low pressure side was maintained at $136 \mathrm{kPa}$ in all permeability measurement experiments.

Hydrogen flux through a dense metallic film may be described by [20]:

$$
N_{H_{2}}=\frac{P_{H}}{h}\left[\boldsymbol{b}_{H} \mathbf{g}-\boldsymbol{b}_{H} \mathbf{g}\right]
$$

where $P_{H}$ is the permeability coefficient, $h$ is the palladium-film thickness and $p_{H}$ with subscripts $\mathrm{H}_{2}$ and $\mathrm{Ar}$ represent the partial pressures of hydrogen on the hydrogen and argon sides of the membrane in the diffusion/permeation cell. When diffusion through the bulk metal is the rate limiting step and hydrogen atoms form an ideal solution in the metal, Sievert's law predicts that $n$ equals to 0.5 . However, a value of $n$ greater than 0.5 may result when surface processes influence the permeation rate or when Sievert's law is not followed.

Based on Eqn. (18), the hydrogen flux data were analyzed to estimate the value of $\mathrm{n}$ by using the Marquardt-Levenberg non-linear least squares method [22]. For the 8.5 and $12 \mu \mathrm{m}$ films, the values of $n$ were estimated as 0.778 and 0.501 , respectively. From this analysis, it appears that a 12 $\mu \mathrm{m}$ palladium film approaches the limiting definition of a dense Pd-film. With values of $n$ equal to 0.778 and 0.501 for the 8.5 and $12 \mu \mathrm{m}$ Pd-film composite membranes, the hydrogen fluxes are plotted against driving force, $\left[\boldsymbol{b}_{H} \mathbf{g}-\boldsymbol{b}_{H} \mathbf{g}\right]$ in Figures 6 and 7, respectively. At a given temperature, the slope of the line provides value of $P_{H} / h$. Since the membrane film thickness is known, one may calculate the membrane permeability from the known slopes of the lines at various temperatures as shown in Figures 6 and 7. From these Figures, it can be seen that the hydrogen fluxes increase with increasing temperature at a given driving force, $\left[b_{H} g-b_{H} g\right]$.

As stated in the previous section, a steady-state counter-diffusion method was used to measure the hydrogen permeability across the composite membrane in which pure hydrogen was used as feed gas on the high pressure side and pure argon was used as sweep gas on the low pressure side. 
Feed side gas sample analysis using the Gas Chromatographic System (Perkin Elmer Sigma 200) did not show any presence of argon (within the detection limit). This suggests that the composite membrane has very high selectivity for hydrogen. This was also confirmed by reversing pressures on the argon and hydrogen sides of the permeation cell.

The permeability coefficient is a strong function of temperature and can be described by an Arrhenius type equation as [23]:

$$
P_{H}=P_{H o} \exp \frac{E_{H}}{R T}
$$

where $P_{H o}$ is the pre-exponential factor in the Arrhenius relationship for hydrogen permeability, $E_{H}$ is the apparent activation energy of hydrogen permeability, $T$ is the absolute temperature and $R$ is the universal gas constant. To correlate the permeability coefficients of the two membranes, permeabilities were plotted against $1 / T$ as shown in Figure 8. The data points correlate very well according to Eqn. (19) since the lines are straight and there is little scatter in the data. From Figure 7, we found that the thicker Pd-film composite membrane has a higher activation energy. The apparent activation energies for the 8.5 and $12 \mu \mathrm{m}$ membranes were estimated to be 5,684 and $12,995 \mathrm{~J} / \mathrm{mol}$, respectively. The pre-exponential factors in the Arrhenius relationship for hydrogen permeability of the 8.5 and $12 \mu \mathrm{m}$ membranes were found to be $4.99 \times 10^{-9} \mathrm{~mol} \cdot \mathrm{m} / \mathrm{m}^{2} \cdot \mathrm{s} \cdot \mathrm{Pa}^{0.778}$ and $6.63 \times 10^{-7} \mathrm{~mol} \cdot \mathrm{m} / \mathrm{m}^{2} \cdot \mathrm{s} \cdot \mathrm{Pa}^{0.501}$.

Our new membrane demonstrated significantly higher hydrogen flux compared to other results on hydrogen flux though composite metal membranes consisting of relatively thin palladium or platinum coating $(30 \mathrm{~mm})$ on hydrogen permeable base metals $[24,25]$ and composite metal microporous membranes $[9,18]$. Table 3 compares measured hydrogen permeability data at specific temperatures with data reported by Collins and Way [18] who used ceramic substrates with $200 \mathrm{~nm}$ pores. Their hydrogen permeability measurements were performed at temperatures in the range of 773 to $873 \mathrm{~K}$. In our work, we used ceramic substrate with $150 \mathrm{~nm}$ pore and hydrogen permeabilities were measured at temperatures in the range of 373 to $573 \mathrm{~K}$. Although the palladium thicknesses were not same, Eqn. (19) can be used to extrapolate hydrogen permeabilities to other temperatures.

Table 4 presents computed hydrogen permeabilities of our membranes at the temperatures used by Collins and Way [18]. The results show that the electroless plated palladium-ceramic composite membranes developed in this work provide significantly higher hydrogen permeability. For example, Collins and Way [18] reported measured hydrogen permeabilities as 
$6.82 \times 10^{-9} \mathrm{~mol} \cdot \mathrm{m} / \mathrm{m}^{2} \cdot \mathrm{s} \cdot \mathrm{Pa}^{0.573}$, and $3.23 \times 10^{-9} \mathrm{~mol} \cdot \mathrm{m} / \mathrm{m}^{2} \cdot \mathrm{s} \cdot \mathrm{Pa}^{0.580}$ at $823 \mathrm{~K}$ for palladium film thicknesses of 17 and $11.4 \mu \mathrm{m}$, respectively on microporus ceramic substrates. At the same temperature, our membranes with palladium film thicknesses of 12 and $8.5 \mu \mathrm{m}$ showed hydrogen permeability of $9.52 \times 10^{-8} \mathrm{~mol} \cdot \mathrm{m} / \mathrm{m}^{2} \cdot \mathrm{s} \cdot \mathrm{Pa}^{0.501}$, and $2.14 \times 10^{-9} \mathrm{~mol} \cdot \mathrm{m} / \mathrm{m}^{2} \cdot \mathrm{s} \cdot \mathrm{Pa}^{0.778}$, respectively. Because of the higher permeability and thinner Pd-films, the new membranes developed here are capable of giving higher hydrogen flux at comparable operating pressures. The thickness of Pd-film dictates the hydrogen flux through the composite membrane.

Permeability studies were conducted using pure hydrogen, helium, argon and carbon dioxide and 50\%/50\% (vol) mixture gases of hydrogen/nitrogen and hydrogen/methane. A detailed permeability experiments were conducted at temperatures of $473 \mathrm{~K}, 573 \mathrm{~K}$ and $673 \mathrm{~K}$ using a palladium-ceramic composite membranes with the $9.77 \mu \mathrm{m}$ palladium film. The results were compared with a hydrogen-selective ceramic membrane commercially available from Velterop Co. The pressure on feed side ranged from $136 \mathrm{kPa}$ to $274 \mathrm{kPa}$. Permeate side pressure was maintained at $101 \mathrm{kPa}$ for all permeability measurement experiments.

Hydrogen and helium flux data were analyzed by nonlinear regression analysis of Eqn. (18) and the results are shown in Figures 9 and 10, respectively. The $n$ values obtained from non-linear analysis were 0.513 and 1.1 for hydrogen and helium, respectively.

Experiments with feed gas mixtures of hydrogen/nitrogen and hydrogen/methane were conducted to test for the presence of gas phase mass transfer resistance. By using nonlinear regression analysis of Eqn. (1), the values of $n$ which best fit the combined temperature data are 0.623 for the hydrogen/nitrogen mixture gas and 0.564 for the hydrogen/methane mixture gases. Figures 11 and 12 show the effects of driving force on hydrogen flux at various temperatures for hydrogen/nitrogen and hydrogen/methane mixture gases, respectively. The experiments were conducted at the same conditions as for the pure gases. However, $n$ values of mixture gases are higher than $n$ value of pure gas. This is due to the accumulation of nondiffusing gas on the feed side of the membrane restricting hydrogen diffusion.

The selectivity is defined as the ratio of the hydrogen flux to the flux of another less permeable gas at the same transmembrane pressure difference. Hydrogen/carbon dioxide, hydrogen/argon and hydrogen/helium selectivities for this membrane are summarized in Figures 13,, 14 and 15, respectively. Hydrogen/carbon dioxide and hydrogen/argon selectivities at $473 \mathrm{~K}$ range from infinity 
at a pressure difference of $35 \mathrm{kPa}$ to 600 at a pressure difference of $173 \mathrm{kPa}$. The average hydrogen/helium selectivities range from 18 to 11 at $473 \mathrm{~K}$ - $673 \mathrm{~K}$ for pressure differences from 35 $\mathrm{kPa}$ to $175 \mathrm{kPa}$. From hydrogen/carbon dioxide and hydrogen/argon selectivity data, we conclude that leakage through membrane defects is minimal. However, the ratio of the defect pore diameter to the molecular mean free path for helium is much less than 0.2. Helium through defect is governed by Knudsen diffusion. Therefore, the minimal defects still lead helium flux significantly higher than flux of argon and carbon dioxide.

To make a comparison, we conducted permeability experiments at the same operating conditions as for a hydrogen-selective ceramic membrane with a $2 \mu \mathrm{m} \gamma$-alumina layer which was commercially available (Velterop Co.). Figures 16, 17 and 18 show the selectivities of hydrogen/helium, hydrogen/carbon dioxide, and hydrogen/argon for the hydrogen-selective ceramic membrane, respectively. For the ceramic membrane, the selectivity of hydrogen/helium increases with decreasing temperature, but selectivities of hydrogen/carbon and hydrogen/argon decrease with decreasing temperature which was unexpected. At this time, we do not have any explanation for this. Comparing Figure 16 with Figure 13, Figure 17 with Figure 14 and Figure 18 with Figure 15, we can see that the selectivities of hydrogen/helium and hydrogen/carbon dioxide or hydrogen/argon for the palladium-ceramic composite membrane are about 14 and 200 times higher than that for the

The mathematical models of cocurrent flow and countercurrent flow patterns discussed in the Mathematical Model Section were used to predict the data from permeability study experiments for hydrogen/nitrogen mixture gas at $573 \mathrm{~K}$. In the model calculation, the selectivity was 800 and power-index was 0.623 . The stage cuts were determined from experimental data. The results of two models were almost identical. The mole fraction on both permeate and reject streams vs. pressure ratio for results of experiments and calculations by using cocurrent and countercurrent flow models are plotted in Figure 19 and Figure 20, respectively. The results show that the predicted product purity is higher than the actually product purity and that the hydrogen mole fraction in reject stream is lower than the measured hydrogen mole fraction. These results indicate that gas phase mass transfer restricts hydrogen diffusion. The difference between predicted and actual mole fraction is less than $12 \%$. Therefore, the models are relatively accurate in predicting the performance of the membrane module and adequate for evaluating the performance of a single-stage membrane permeator. 


\section{CONCLUSIONS}

In this study, electroless plating of palladium was used to fabricate thin-film Pd-ceramic composite membranes. Permeability measurements at elevated temperatures and pressures showed that the composite membrane has a very high permeability and selectivity for hydrogen. The thickness of Pd-film dictates the hydrogen flux through the composite membrane. As the film thickness increases, it must be analyzed as thick dense metallic film. Using the electroless plating method developed in this work, it appears that a film thickness of $12 \mu \mathrm{m}$ approaches the limit of dense film (with index $n$ estimated as 0.501 ). A mathematical model is developed to describe the performance of a single-staged cocurrent and countercurrent membrane permeation cell. We believe that the new Pd-ceramic composite membrane has great potential for high temperature hydrogen separations and membrane reactors if a fabrication process can be perfected. A mathematical model is developed to describe the performance of a single-staged cocurrent and countercurrent membrane permeation cell. 


\section{ACKNOWLEDGMENTS}

This research was sponsored by the Pittsburgh Energy Technology Center, U.S. DOE under grant number DE-FG22-93MT93008. The authors wish to thank their industrial collaborator, Amoco Chemical Company - R\&D Center, Naperville. In particular, the support of Drs. Carl Udovich, Gary P. Hagen and Vasu Kulkarni, is greatly appreciated. The project also supported (fully/partially) following graduate students in completing their MSE degrees:

Udo Ita Udo-Aka, "Evaluation of Electroless Plated Thin-Film Palladium-Ceramic Composite Membrane for Hydrogen Gas Separation," MSE Thesis, NCA\&TSU, North Carolina (1995).

Nan $\mathrm{Su}$, "Preparation and Characterization of Pd-Ceramic Composite Membrane for High Temperature Gas Separation," MSE Thesis, NCA\&TSU, North Carolina (1995).

Sabita Roy, "Modeling and Analysis of Membrane Modules for the Separation of Hydrogen Using Pd-Ceramic Composite Membrane," MSE Thesis, NCA\&TSU, North Carolina (1996).

Tingfang Fan, "Perm-selectivity of Hydrogen Through Electroless Deposited Thin-film PalladiumCeramic Composited Membrane,” MSE Thesis, NCA\&TSU, North Carolina (1997). 


\section{NOMENCLTURE}

$F_{o} \quad$ Ratio of sweep / reject flow rate

$F_{f} \quad$ Ratio of sweep / feed flow rate

$h \quad$ Membrane thickness

$J \quad$ Flux

$L \quad$ Feed-side flow rate

$L_{f} \quad$ Inlet feed flow rate

$L_{o} \quad$ Reject flow rate

$P \quad$ Feed-side pressure

p Permeate-side pressure

$p_{a} \quad$ Permeability of more permeable component A

$p_{b} \quad$ Permeability of less permeable component B

$R \quad$ Dimensionless membrane area

$S \quad$ Actual membrane area

$T \quad$ Temperature

$V \quad$ Permeate-side flow rate

$V_{s} \quad$ Sweep gas flow rate

$V_{p} \quad$ Permeate flow rate

$x_{a} \quad$ Mole fraction of more permeable component $\mathrm{A}$ in feed-side stream

$x_{a f} \quad$ Mole fraction of more permeable component $\mathrm{A}$ in feed stream

$x_{a o} \quad$ Mole fraction of more permeable component A in reject stream

$x_{i} \quad$ Mole fraction of nonpermeable components in feed-side stream

$x_{i f} \quad$ Mole fraction of nonpermeable components in feed gas stream

$x_{i o} \quad$ Mole fraction of nonpermeable components in reject stream

$y_{a} \quad$ Mole fraction of more permeable component $\mathrm{A}$ in permeate-side stream

$y_{a s} \quad$ Mole fraction of more permeable component A in permeate-side stream

$y_{a p} \quad$ Mole fraction of more permeable component A in permeate-side stream 
$y_{i} \quad$ Mole fraction of nonpermeable components in permeate-side stream

$y_{i s} \quad$ Mole fraction of nonpermeable components in permeate-side stream

$y_{i p} \quad$ Mole fraction of nonpermeable components in permeate-side stream

$\gamma \quad$ Permeate / feed pressure ratio

$\alpha \quad$ Membrane selectivity 


\section{REFERENCES}

1. Li, D., and Hwang, S-T., "Gas Separation by Sillicon based Inorganic Membrane at High Temperature,” J. Memb. Sci., 66, 119 (1992).

2. Shu, J., Grandjean, B.P.A., Neste, A.V., and Kallagune, S., "Catalytic Palladium-based Membrane Reactors: A Review," Can. J. Chem. Eng., 69, 1036 (1991).

3. Itoh, N., Xu, W-C., and Haraya, K., "Basic Experimental Study on Palladium Membrane Reactors," J. Memb. Sci., 66, 149 (1992).

4. Edlund, D.J., and Pledger, W.A., "Thermolysis of Hydrogen Sulfide in a Metal-Membrane Reactor," J. Memb. Sci., 77, 255 (1993).

5. Mohan, K., and Govind, R., "Analysis of Equilibrium Shift in Isothermal Reactors with a Permselective Wall," AIChE J., 34(9), 1493 (1988).

6. Hsieh, P., "Inorganic Membrane Reactors: A Review," AIChE Symposium Series 268, 85, 268 (1989).

7. Zaspalis, V.T., and Burggraaf,A.J., "Inorganic Membrane Reactors to Enhance the Productivity of Chemical Processes," in Inorganic Membrane: Synthesis, Characteristics, and Applications, R.R. Bhave (ed.), Van Nostrand Reinhold, New York (1991).

8. Itoh N., and Govind R., "Development of a Novel Oxidative Palladium Membrane Reactor," AIChE Symposium Series 268, 85, 10 (1989).

9. Uemiya, S., Sato, N., Ando, H., Kude, Y., Matsuda, T., and Kikuchi, E., "Separation of Hydrogen Through Palladium Thin-film Supported on a Porous Glass Tube," J. Memb. Sci., 56, 303 (1991).

10. Itoh, N., Shindo, Y., Haraya, K., and Hakuta, T., "A Membrane Reactor Using Microporous Glass for Shifting Equilibrium of Cyclohexane dehydrogenation," J. Chem. Eng. Japan, 21(4), 399 (1988).

11. Itoh, N., "Development of a One-side Uniform Model for Palladium Membrane Reactors," J. Chem. Eng. Japan, 25(3), 336 (1992).

12. Ohata, Y., Gondaira M., Kobayashi K., Fujimoto, Y., and Kuroda, K., "Study on the Performance of a Stream Reformer of Town Gas Equipped with Palladium Membranes," 1994 AIChE Annual Meeting, San Francisco, Paper No. 76i (1994).

13. Ilias, S., and Govind, R., "Development of High Temperature Membrane for Membrane Reactor: an Overview," AIChE Symposium Series 268, 85, 18 (1989). 
14. Ilias, S., King, F.G., and Su, N., "Separation of Hydrogen Using Thin Film Palladium-Ceramic Composite Membrane," Proc. Coal-Fired Power Systems '95, Morgantown, WV, vol. II, pp. 646-654 (1995).

15. Ilias, S., Su, N., Udo-Aka, U.I., and King, F.G., "Application of Electroless Deposited Thinfilm Palladium Composite Membrane in Hydrogen Separation," Sep. Sci. Tech., 32, 487 (1997).

16. Ohno, I, "Electrochemistry of Electroless Plating," Materials Science and Engineering, A146, 33 (1991).

17. Rhoda, R.N., "Electroless Palladium Plating," Trans. Inst. Met. Fin., 36, 82 (1959).

18. Collins, J.P., and Way, J.D., "Preparation and Characterization of a Composite PalladiumCeramic Membrane," Ind. Eng. Chem. Res., 32, 3006 (1993).

19. Riedel, W., "Electroless Nickel Plating," ASM International, Ohio, 1991.

20. Uemiya, S., Sato, N., Ando, H., and Kikuchi, E., "The Water Gas Shift Reaction Assisted by a Palladium-Permeable Membrane Reactor," App. Cat., 67, 223 (1991).

21. Fan, T., MSE Thesis, NCA\&TSU, North Carolina (1996).I

22. Ralston, A., and Rabinowitz, P., "A First Course in Numerical Analysis," 2nd ed., McGrawHill, New York, 1978.

23. Barrer, R.M., "Diffusion In and Through Solids," Cambridge University Press, London, 1941.

24. Edlund, J.D., "A Catalytic Membrane Reactor for Facilitating the Water-Gas Shift Reaction at High-Temperature," Proc. Coal-Fired Power Systems 94 -Advances in IGCC and PFBC Review Meeting, Morgantown, WV, vol. II, pp. 709-13 (1994).

25. Buxbaum, R.E., and Marker, T.L., "Hydrogen Transport Through Non-porous Membranes of Palladium Coated Niobium Tantalum and Vanadium," J. Memb. Sci., 85, 29 (1993). 
TABLE 1. Typical Electroless Plating Bath Composition

\begin{tabular}{||l|l||}
\hline Component/Variables & Concentration \\
\hline \hline Palladium chloride & $5.4 \mathrm{~g} / 1$ \\
\hline Ammonium hydroxide $(5 \mathrm{~N})$ & $290 \mathrm{ml} / 1$ \\
\hline Hydrazine $(1 \mathrm{molar}$ solution) & $10 \mathrm{ml} / 1$ \\
\hline EDTA & $40 \mathrm{~g} / 1$ \\
\hline PH & 11 \\
\hline Temperature & $120^{\circ} \mathrm{C}$ \\
\hline \hline
\end{tabular}

TABLE 2. Composition of Sensitization and Activation Solutions

\begin{tabular}{||c|c||c|c||}
\hline \multicolumn{2}{|c||}{ Sensitization Solution } & \multicolumn{2}{c||}{ Activation Solution } \\
\hline Component & Concentration & Component & Concentration \\
\hline \hline $\mathrm{SnCl}_{2}$ & $1 \mathrm{~g} / 1$ & $\mathrm{PdCl}_{2}$ & $0.09 \mathrm{~g} / 1$ \\
\hline $\mathrm{HCl}$ & $0.2 \mathrm{~N}$ & $\mathrm{HCl}$ & $0.2 \mathrm{~N}$ \\
\hline
\end{tabular}


TABLE 3. Summary of Hydrogen Permeability Data at Specific Temperatures for PalladiumCeramic Composite Membranes.

\begin{tabular}{|c|c|c|c|c|}
\hline Membrane Description & $\begin{array}{c}\text { Temperature } \\
(\mathrm{K})\end{array}$ & Permeability, $\mathrm{P}_{\mathrm{H}}$ & $\mathrm{n}$ & Reference \\
\hline $\begin{array}{l}8.5 \mu \mathrm{m} \text { palladium film on } \\
\text { ceramic membrane with } \\
150 \mathrm{~nm} \text { pore }\end{array}$ & $\begin{array}{l}373 \\
473 \\
573 \\
\end{array}$ & $\begin{array}{l}7.62 \times 10^{-10} \\
1.16 \times 10^{-9} \\
1.46 \times 10^{-9}\end{array}$ & $\begin{array}{l}0.778 \\
0.778 \\
0.778 \\
\end{array}$ & This work \\
\hline $\begin{array}{l}12 \mu \mathrm{m} \text { palladium film on } \\
\text { ceramic membrane with } \\
150 \mathrm{~nm} \text { pore }\end{array}$ & $\begin{array}{l}373 \\
473 \\
573\end{array}$ & $\begin{array}{l}8.84 \times 10^{-9} \\
2.47 \times 10^{-8} \\
3.87 \times 10^{-8}\end{array}$ & $\begin{array}{l}0.501 \\
0.501 \\
0.501\end{array}$ & This work \\
\hline $\begin{array}{l}17 \mu \mathrm{m} \text { palladium film on } \\
\text { ceramic membrane with } \\
200 \mathrm{~nm} \text { pore }\end{array}$ & $\begin{array}{l}723 \\
773 \\
823 \\
873\end{array}$ & $\begin{array}{l}2.34 \times 10^{-9} \\
4.04 \times 10^{-9} \\
6.82 \times 10^{-9} \\
9.96 \times 10^{-9}\end{array}$ & $\begin{array}{l}0.573 \\
0.573 \\
0.573 \\
0.573\end{array}$ & [16] \\
\hline $\begin{array}{l}11.4 \mu \mathrm{m} \text { palladium film } \\
\text { on ceramic membrane } \\
\text { with } 200 \mathrm{~nm} \text { pore }\end{array}$ & $\begin{array}{l}823 \\
873\end{array}$ & $\begin{array}{l}3.23 \times 10^{-9} \\
5.84 \times 10^{-9}\end{array}$ & $\begin{array}{l}0.580 \\
0.580\end{array}$ & [16] \\
\hline
\end{tabular}

TABLE 4. Computed Hydrogen Permeability Using $\mathrm{P}_{\mathrm{H}}=\mathrm{P}_{\mathrm{HO}} \exp \left(-\mathrm{E}_{\mathrm{H}} / \mathrm{RT}\right)$ at Indicated Temperatures for New Palladium-Ceramic Composite Membranes.

\begin{tabular}{|c|c|c|c|}
\hline Membrane Description & $\begin{array}{c}\text { Temperature } \\
(\mathrm{K})\end{array}$ & Permeability, $\mathrm{P}_{\mathrm{H}}$ & $\mathrm{P}_{\mathrm{HO}} \frac{\mathrm{mol} \cdot \mathrm{m}}{\mathrm{m}^{2} \cdot \mathrm{s} \cdot \mathrm{Pa}^{\mathrm{n}}}$ \\
\hline $\begin{array}{l}8.5 \mu \mathrm{m} \text { palladium film } \\
\text { on ceramic membrane } \\
\text { with } 150 \mathrm{~nm} \text { pore }\end{array}$ & $\begin{array}{l}773 \\
823 \\
873 \\
\end{array}$ & $\begin{array}{l}2.02 \times 10^{-9} \\
2.14 \times 10^{-9} \\
2.24 \times 10^{-9} \\
\end{array}$ & $\begin{array}{c}\mathrm{P}_{\mathrm{H} 0}=4.99 \times 10^{-9} \\
\mathrm{E}_{\mathrm{H}}=5,684 \\
\mathrm{n}=0.778\end{array}$ \\
\hline $\begin{array}{l}12 \mu \mathrm{m} \text { palladium film } \\
\text { on ceramic membrane } \\
\text { with } 150 \mathrm{~nm} \text { pore }\end{array}$ & $\begin{array}{l}773 \\
823 \\
873\end{array}$ & $\begin{array}{l}8.39 \times 10^{-8} \\
9.52 \times 10^{-8} \\
1.06 \times 10^{-7}\end{array}$ & $\begin{array}{c}\mathrm{P}_{\mathrm{H} 0}=6.63 \times 10^{-7} \\
\mathrm{E}_{\mathrm{H}}=12,995 \\
\mathrm{n}=0.501\end{array}$ \\
\hline
\end{tabular}




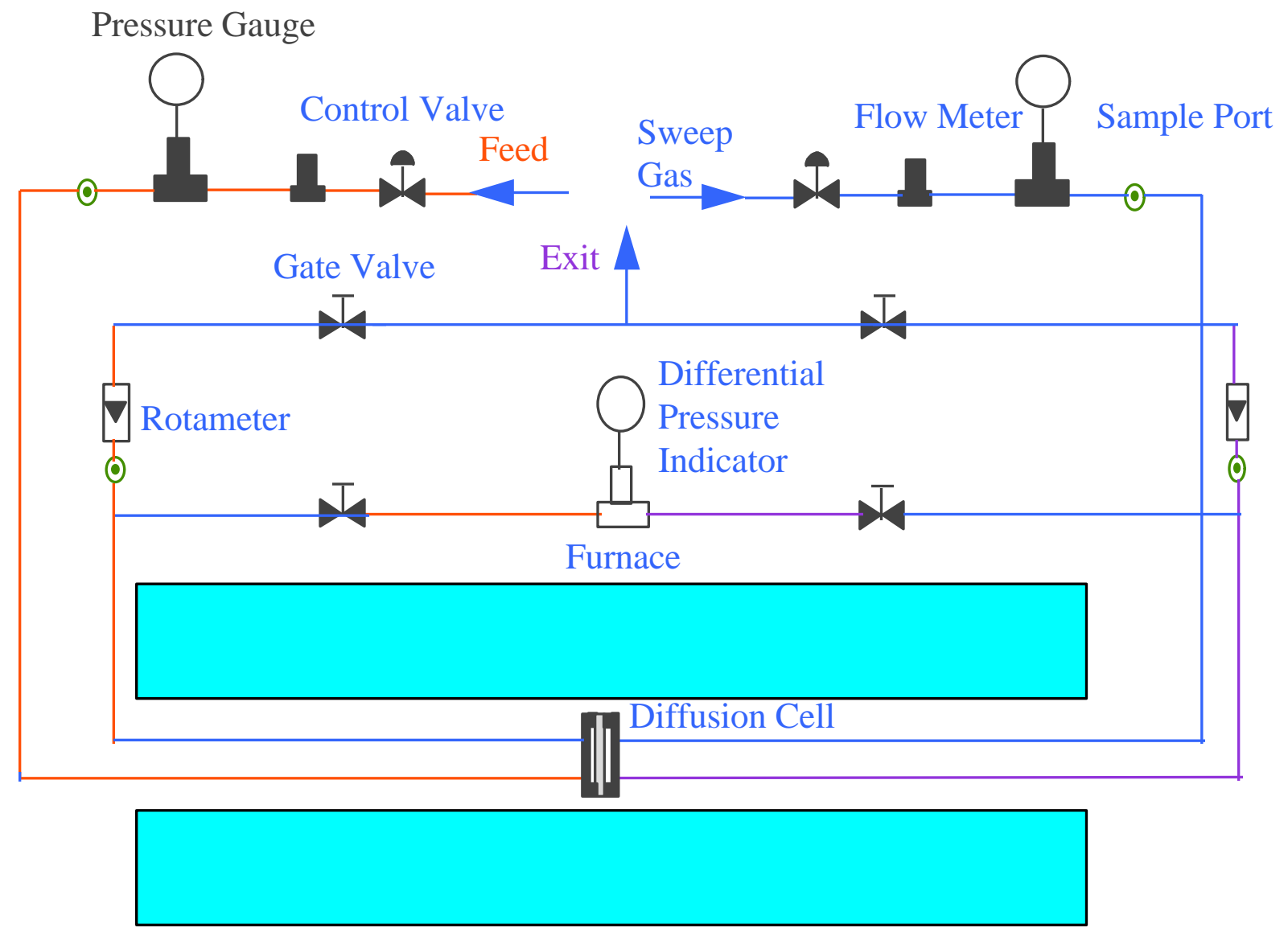

FIGURE 1: Schematic of permeability measurement setup 


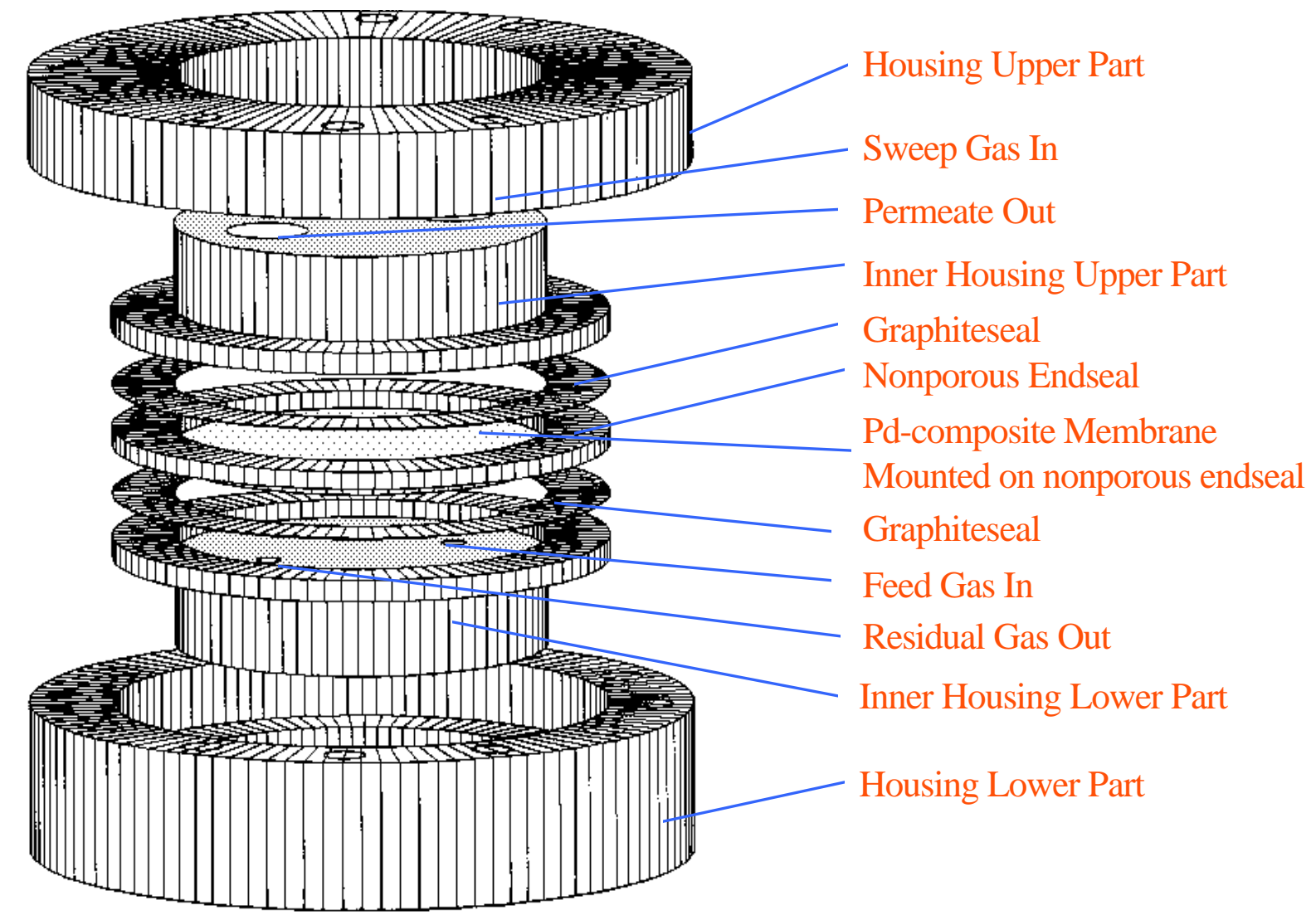

FIGURE 2: Details of diffusion cell 


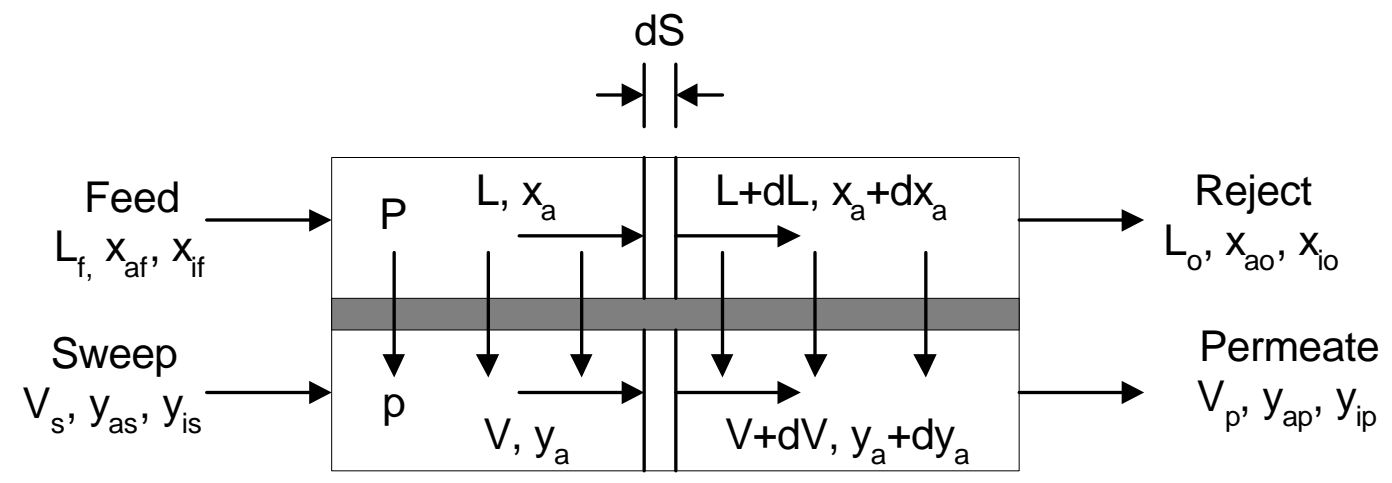

(a) Cocurrent Flow Model

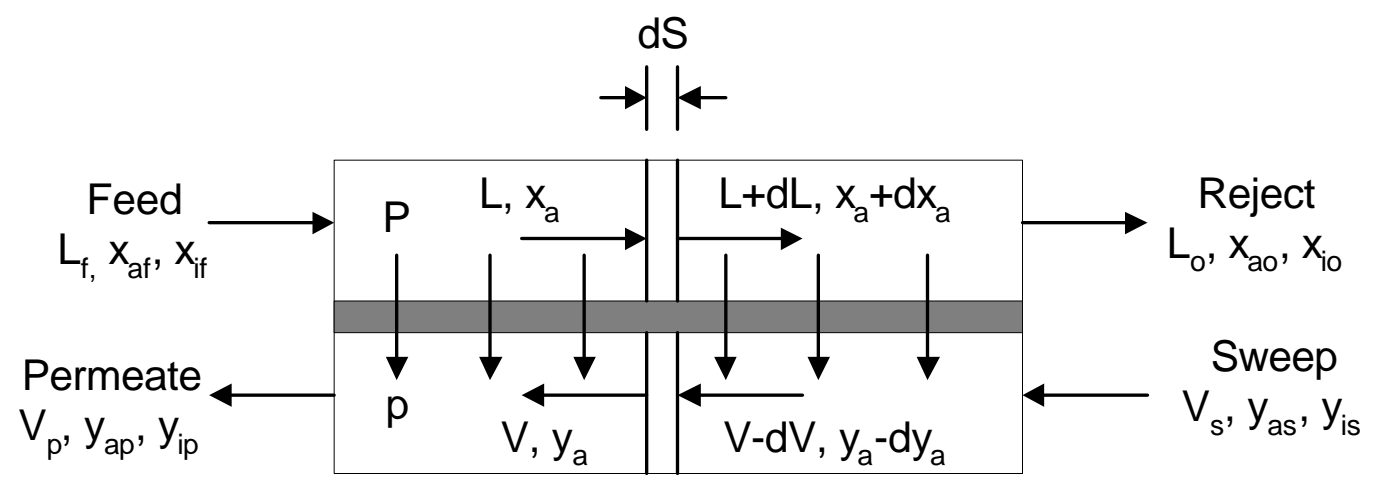

(b) Countercurrent Flow Model

FIGURE 3: Schematic diagrams of flow configurations in single-stage permeation cell: (a) cocurrent, and (b) countercurrent 


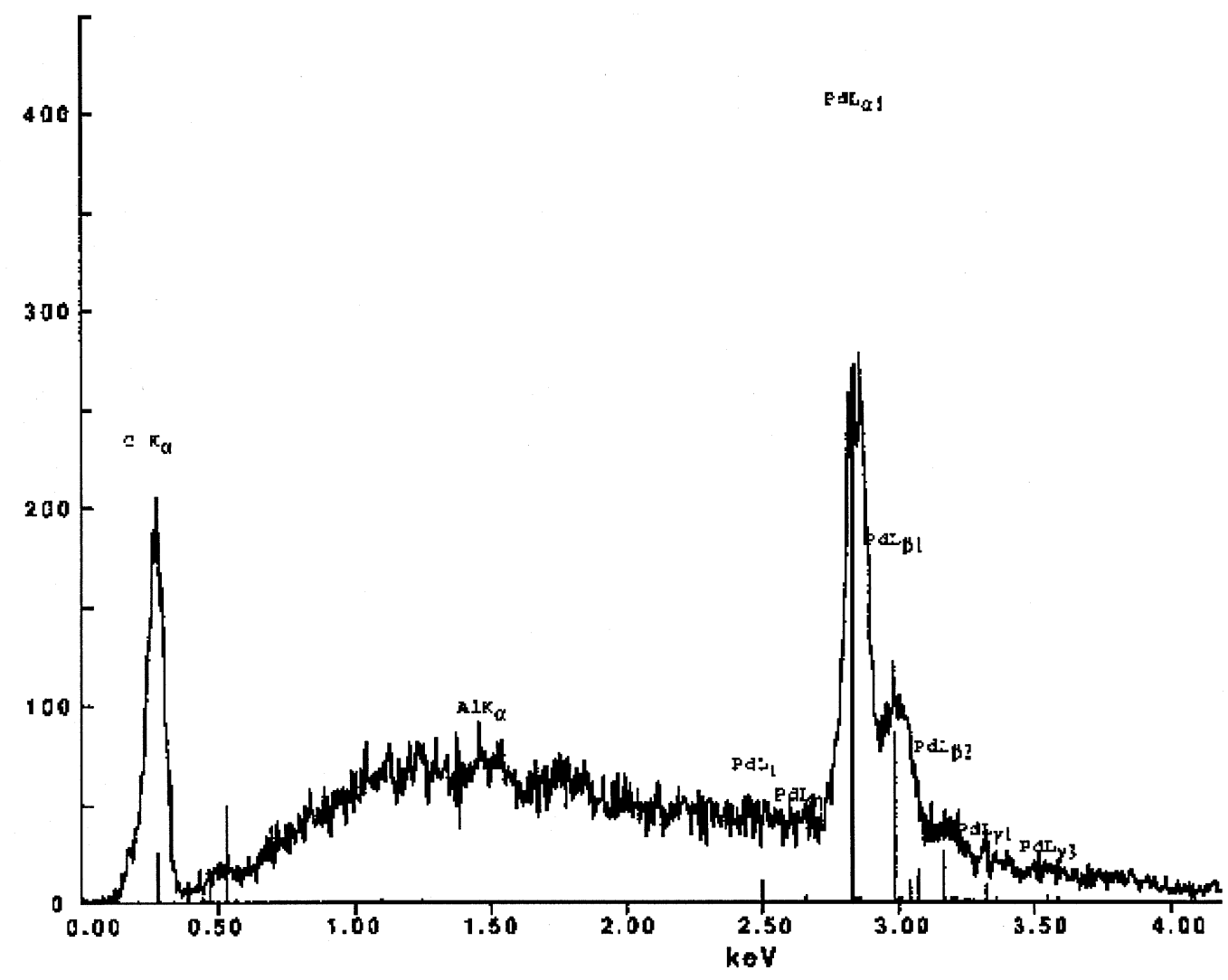

FIGURE 4: Energy Dispersive X-ray (EDX) analysis of electroless deposited palladium film on ceramic substrate 


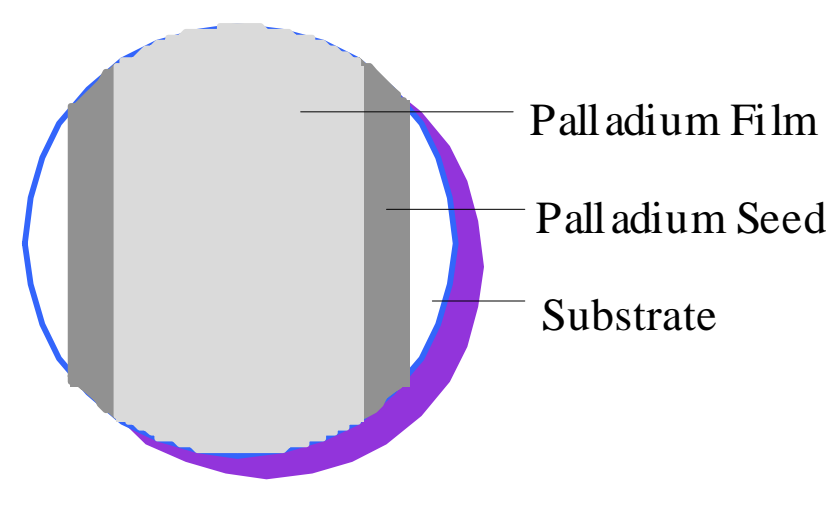

(a) Composite Membrane

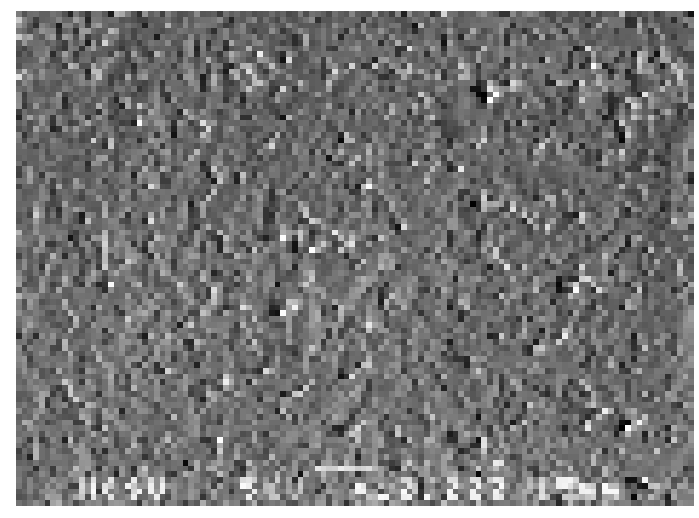

(b) Ceramic Substrate

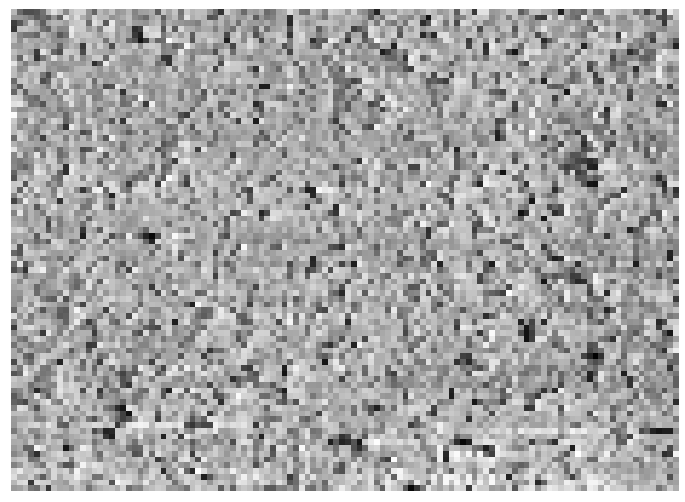

(c) Pal ladium Seed

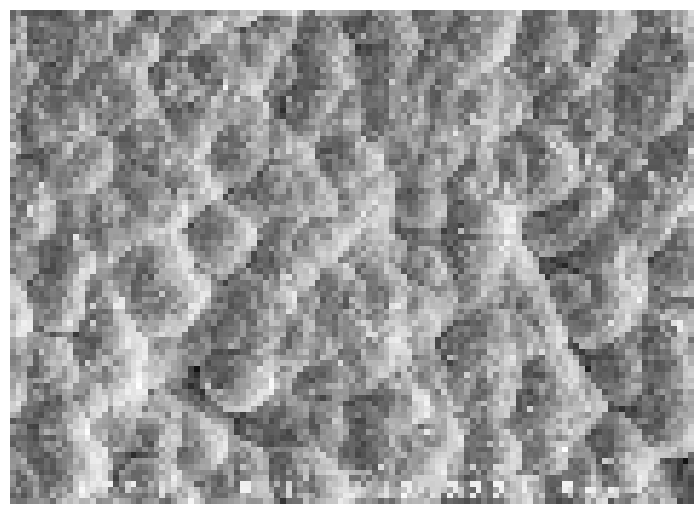

(d) Palladium Film

FIGURE 5: SEM micrographs of Pd-ceramic composite membrane: (a) sample specimen, (b) SEM of substrate, (c) SEM of sensitized and activated substrate surface, and (d) SEM of electroless deposited Pd-film on ceramic substrate 


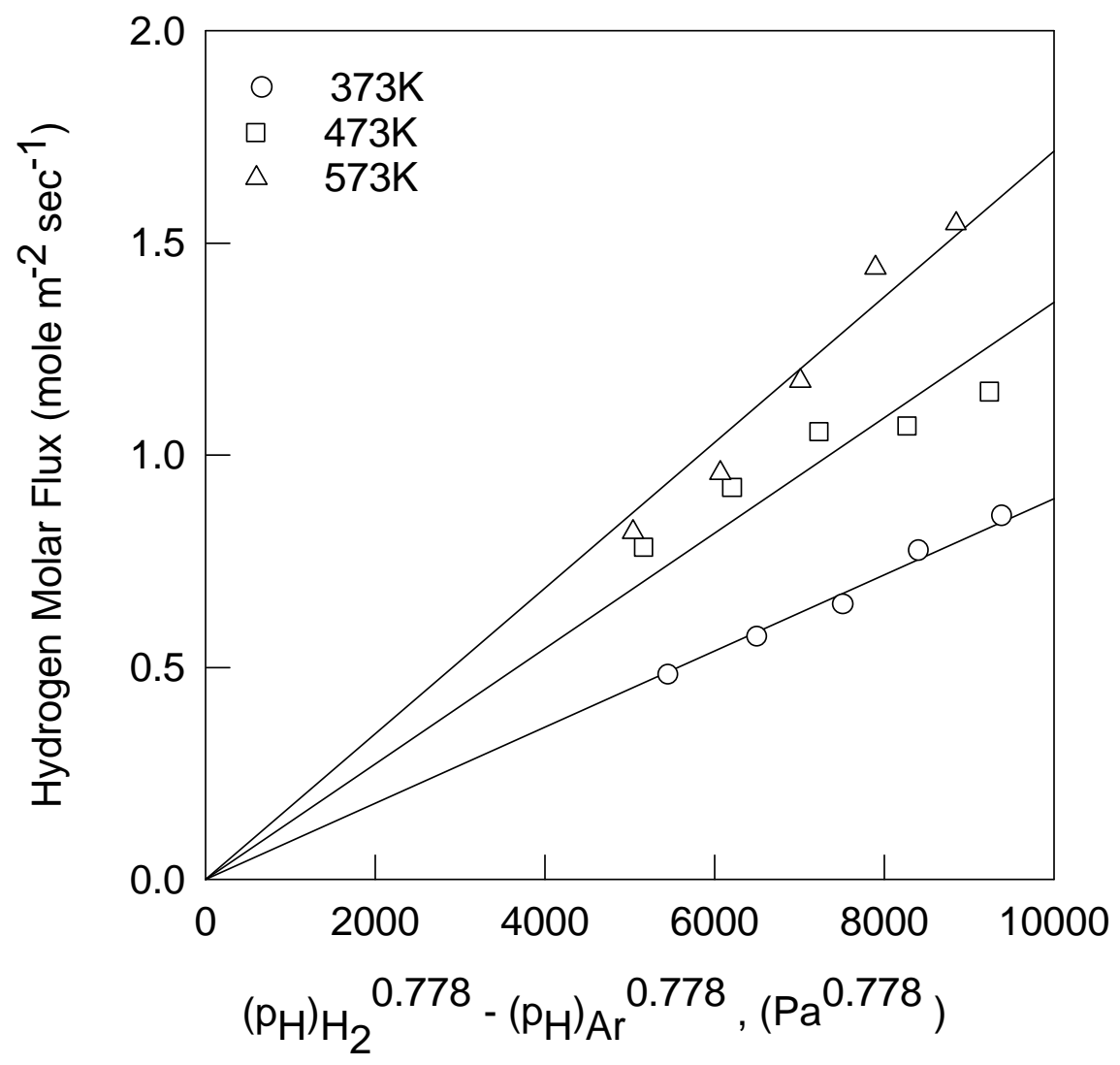

FIGURE 6: Effect of driving force, $\left[p_{H},-p_{H} 9\right]$ on hydrogen permeation fluxes at various temperatures through the palladium-ceramic composite membrane with a film thickness of $8 \mu \mathrm{m}$ and $n=0.778$. 


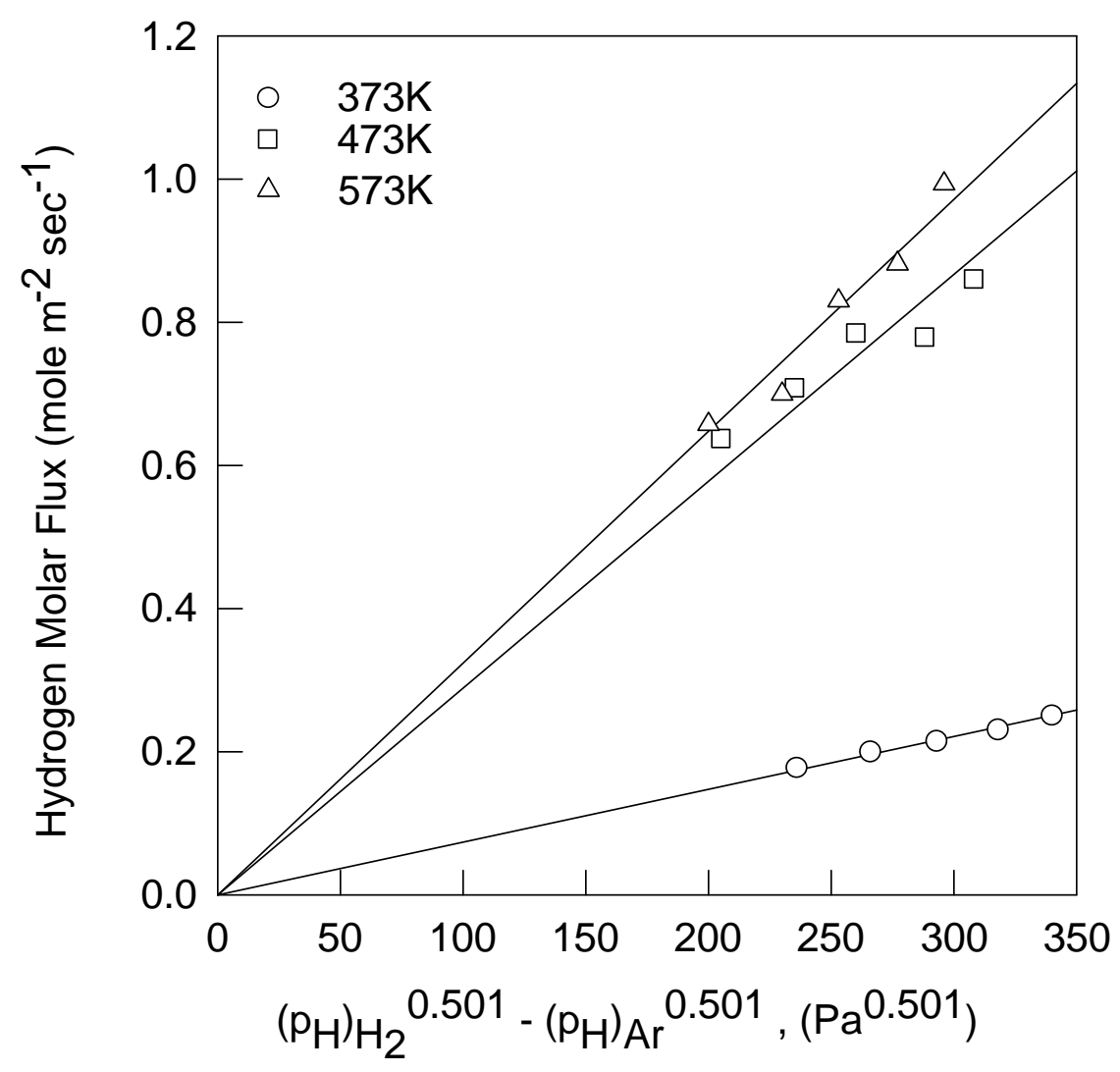

FIGURE 7: Effect of driving force, $\left[\boldsymbol{p}_{H} \mathbf{g}-\boldsymbol{p}_{H} \mathbf{g}\right]$ on hydrogen permeation fluxes at various temperatures through the palladium-ceramic composite membrane with a film thickness of $8 \mu \mathrm{m}$ and $n=0.501$. 


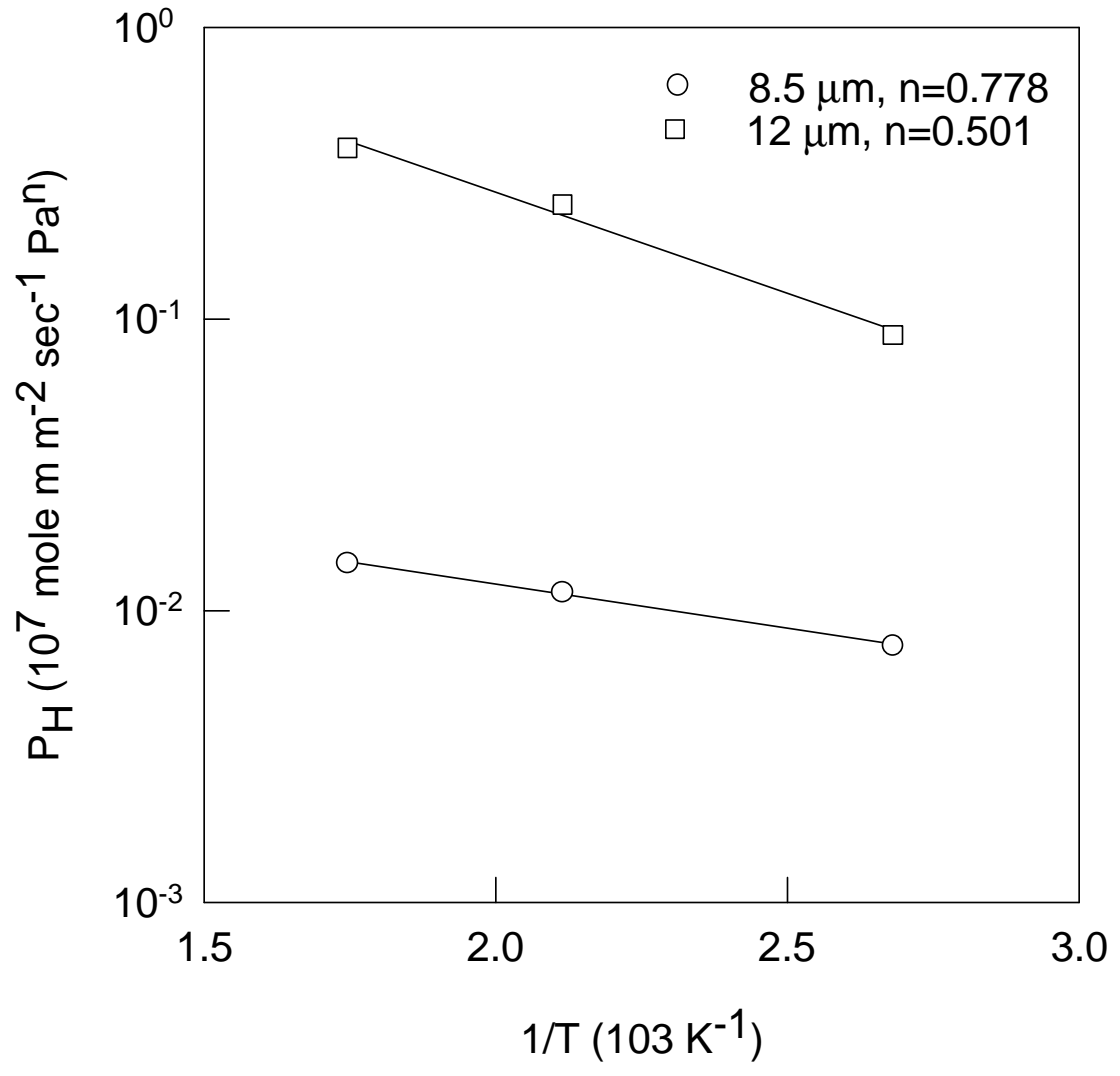

FIGURE 8: Effect of temperature on hydrogen permeability through palladium-ceramic composite membranes. 


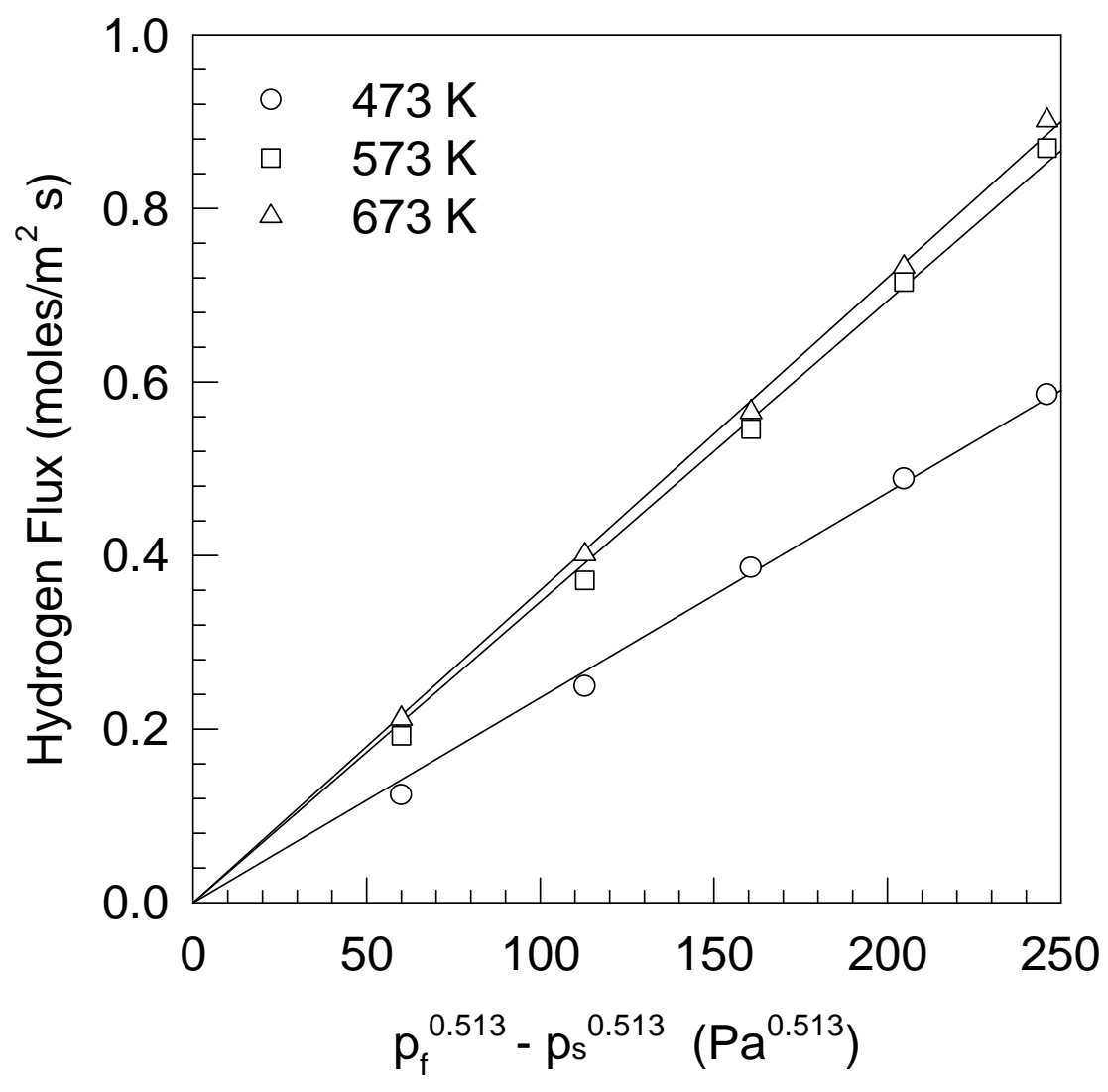

FIGURE 9: Effect of driving force, $\left[\boldsymbol{b}_{H}, \mathbf{g}-\boldsymbol{b}_{H} \mathbf{g}\right]$ on hydrogen permeation fluxes at various temperatures through the palladium-ceramic composite membrane with a film thickness of $9.77 \mu \mathrm{m}$ and $n=0.513$. 


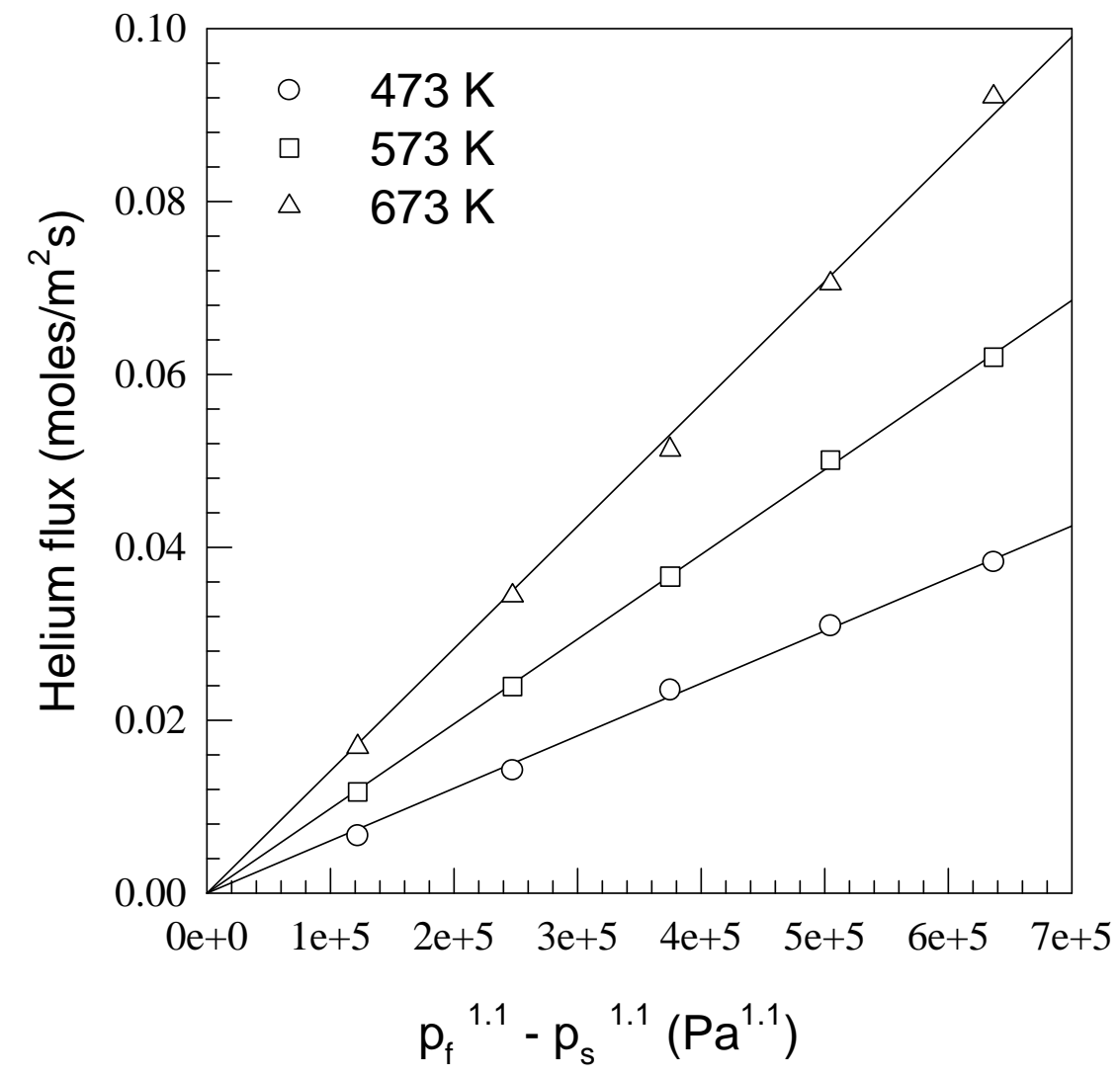

FIGURE 10: Effect of driving force, $\left[\boldsymbol{b}_{H e}, \boldsymbol{g}-\boldsymbol{b}_{H e} \boldsymbol{g}\right]$ on helium permeation fluxes at various temperatures through the palladium-ceramic composite membrane with a film thickness of $9.77 \mu \mathrm{m}$ and $n=1.1$ 


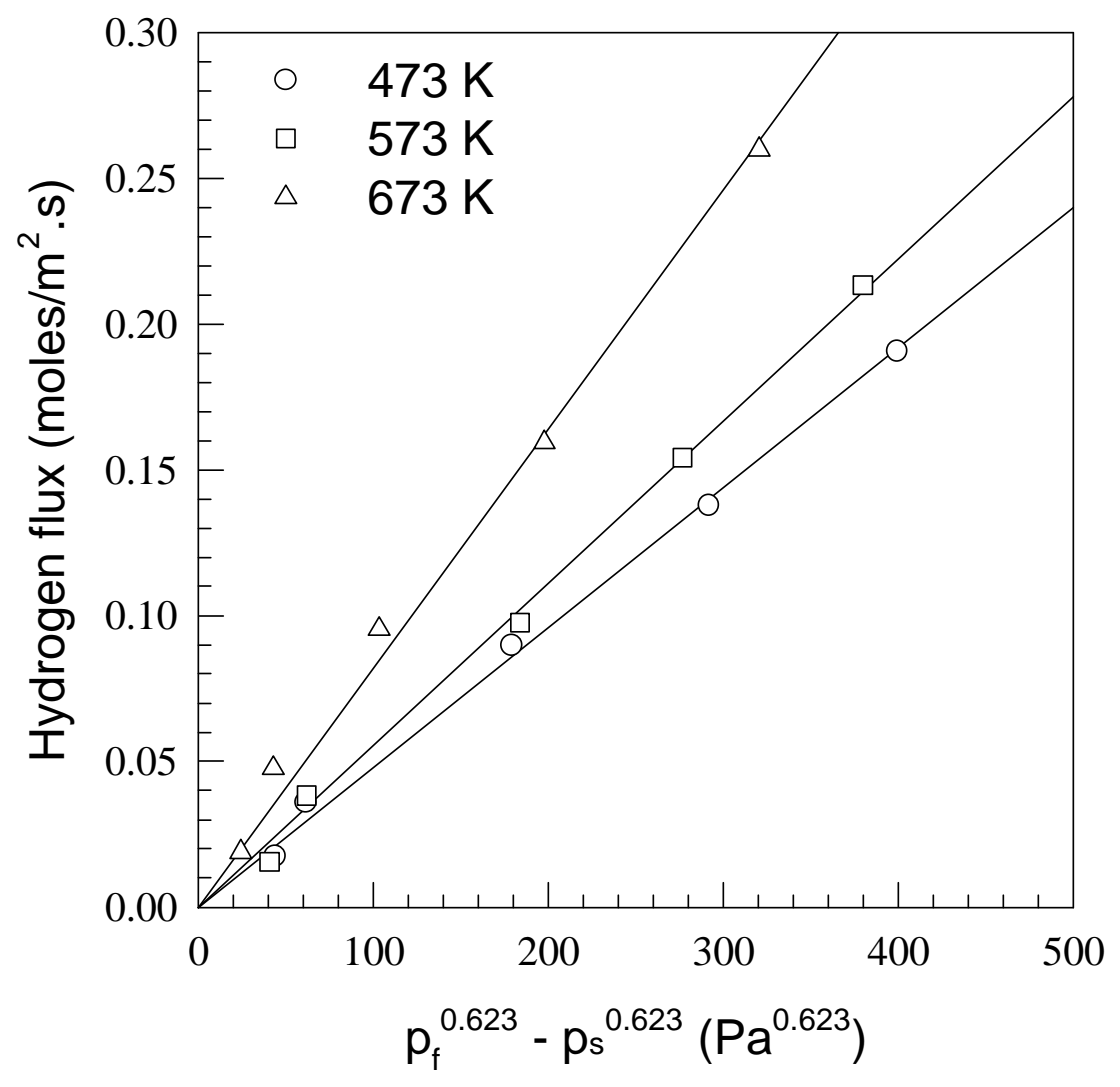

FIGURE 11: Effect of driving force, $\left[\boldsymbol{b}_{H} \underline{9}-\boldsymbol{b}_{H} \mathbf{q}\right]$ on hydrogen permeation fluxes at various temperatures through the palladium-ceramic composite membrane with a film thickness of $9.77 \mu \mathrm{m}$ and $n=0.623$ for $\mathrm{N}_{2} / \mathrm{H}_{2}$ mixture. 


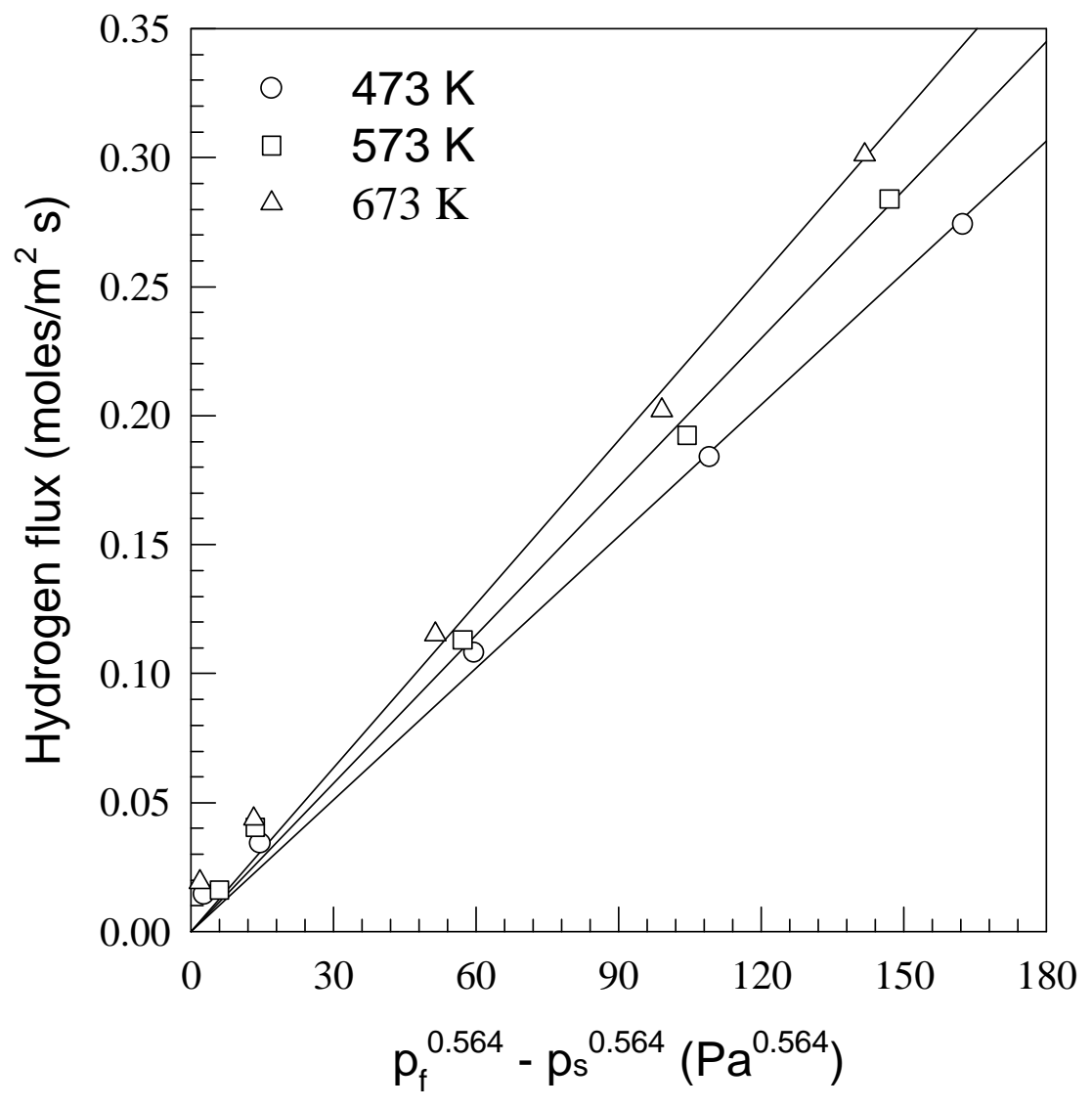

FIGURE 12: Effect of driving force, $\left[\boldsymbol{b}_{H} \boldsymbol{q}-\boldsymbol{b}_{H} \mathbf{g}\right]$ on hydrogen permeation fluxes at various temperatures through the palladium-ceramic composite membrane with a film thickness of $9.77 \mu \mathrm{m}$ and $n=0.564$ for $\mathrm{CH}_{4} / \mathrm{H}_{2}$ mixture. 


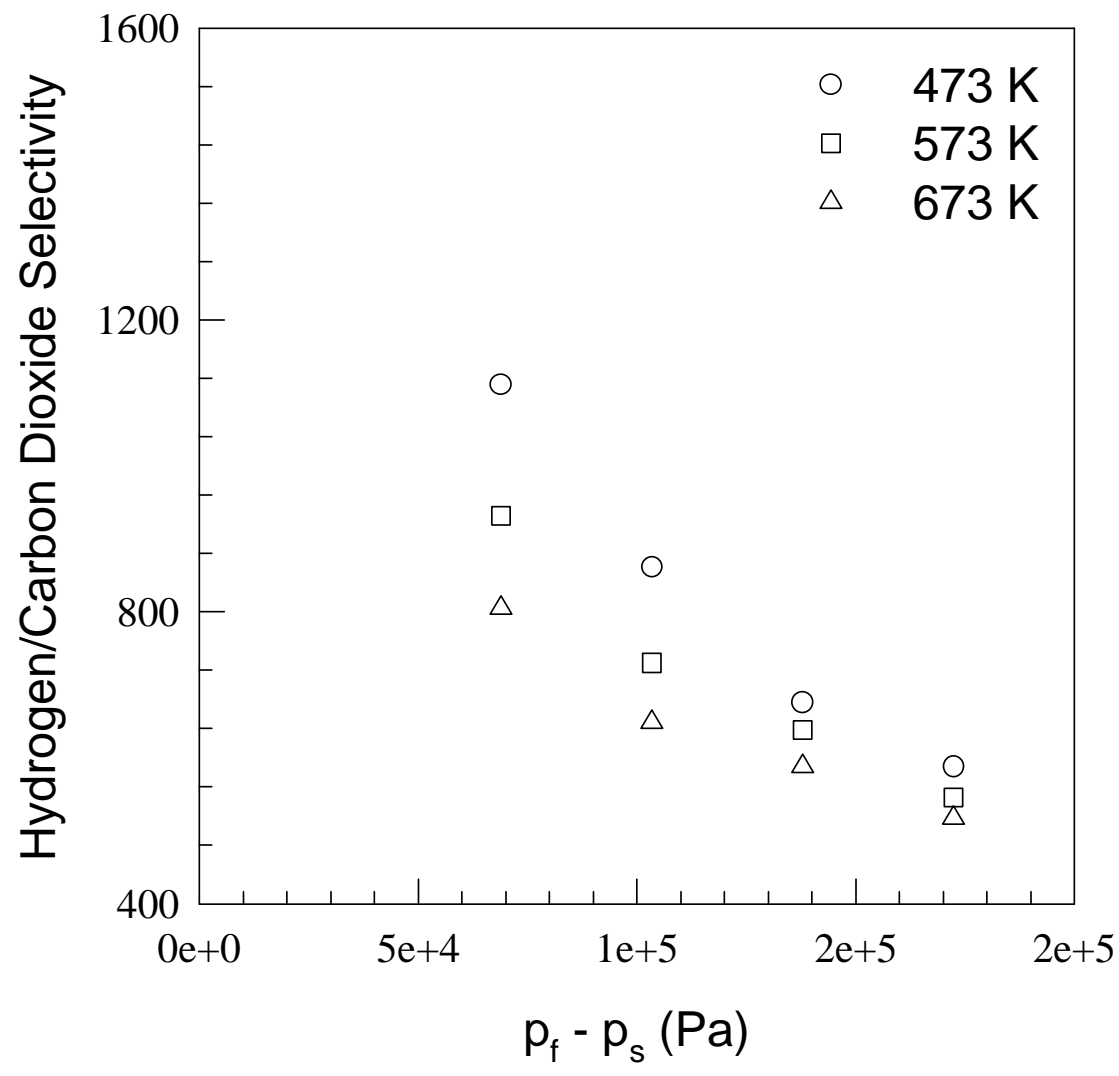

FIGURE 13: Effect of transmembrane pressure difference $\left[b_{H} g-b_{H} g\right]$ on hydrogen/carbon dioxide selectivity at various temperatures for palladium-ceramic composite membrane with $9.77 \mu$ mpalladium film for pure gases. 


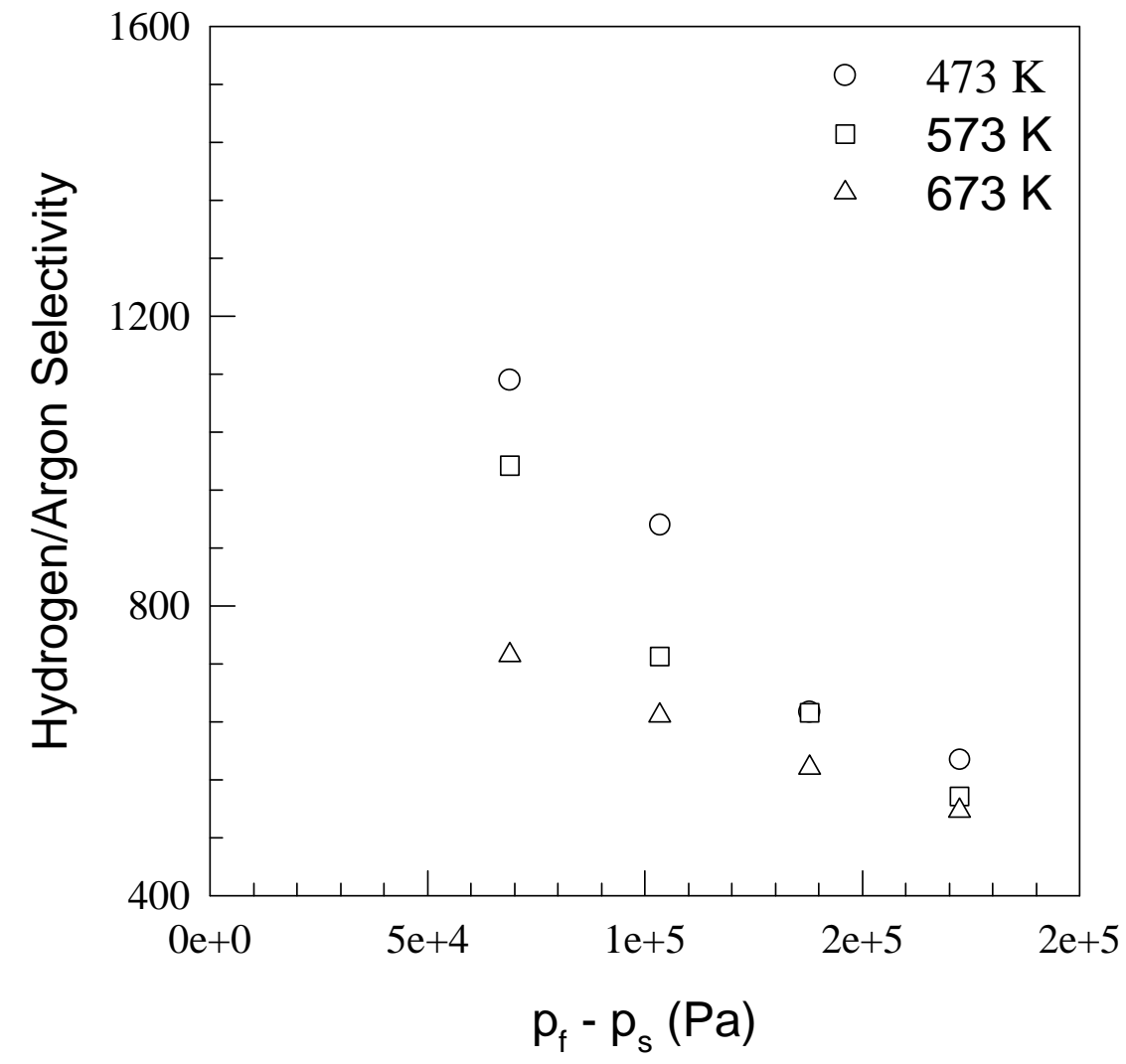

FIGURE 14: Effect of transmembrane pressure difference $\left[p_{H} \mathbf{q} b_{H} \mathbf{g}\right.$ on hydrogen/argon selectivity at various temperatures for palladium-ceramic composite membrane with $9.77 \mu \mathrm{m}$ palladium film for pure gases. 


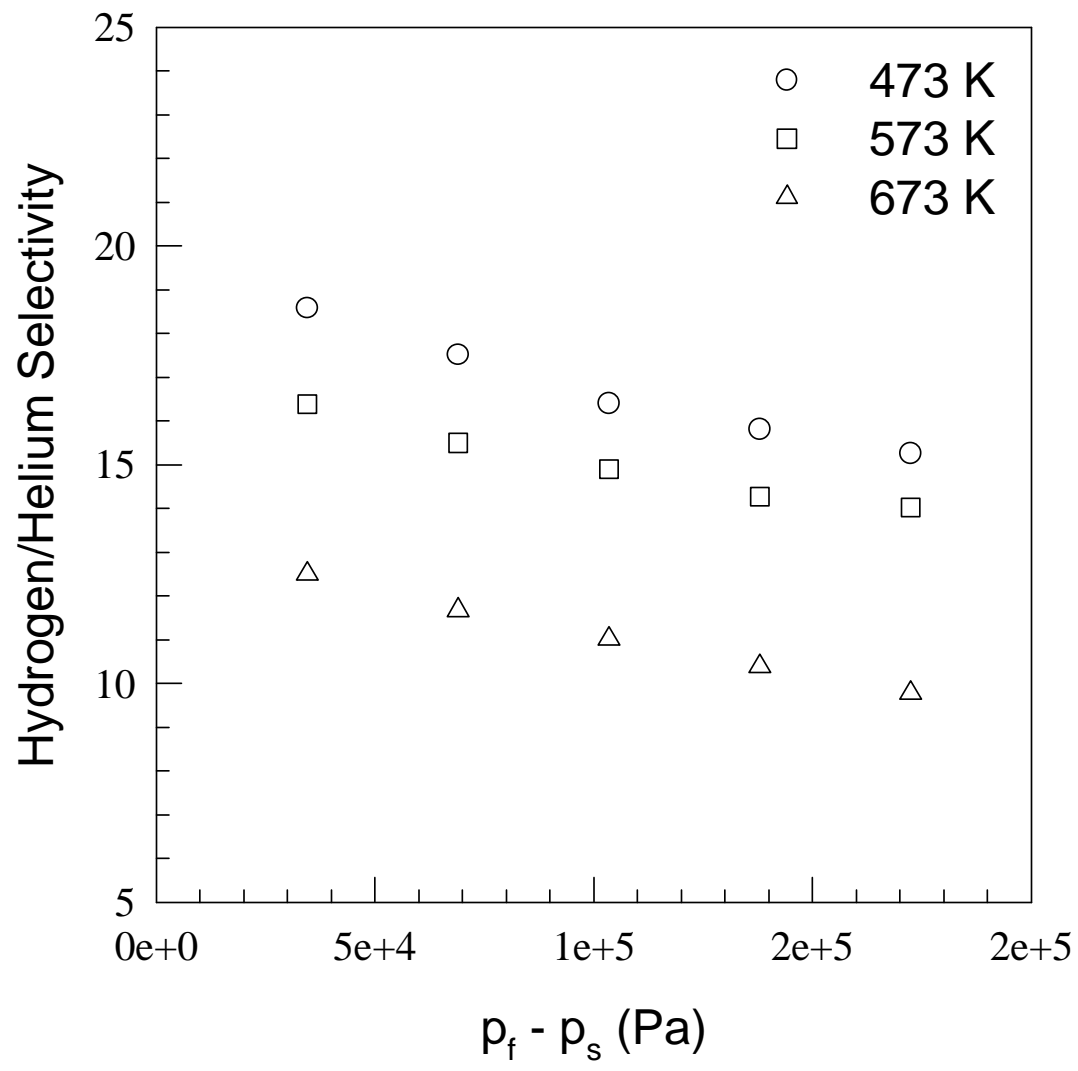

FIGURE 15: Effect of transmembrane pressure difference $\left[\boldsymbol{p}_{H} g-\boldsymbol{p}_{H} g\right]$ on hydrogen/argon selectivity at various temperatures for palladium-ceramic composite membrane with $9.77 \mu$ mpalladium film for pure gases. 


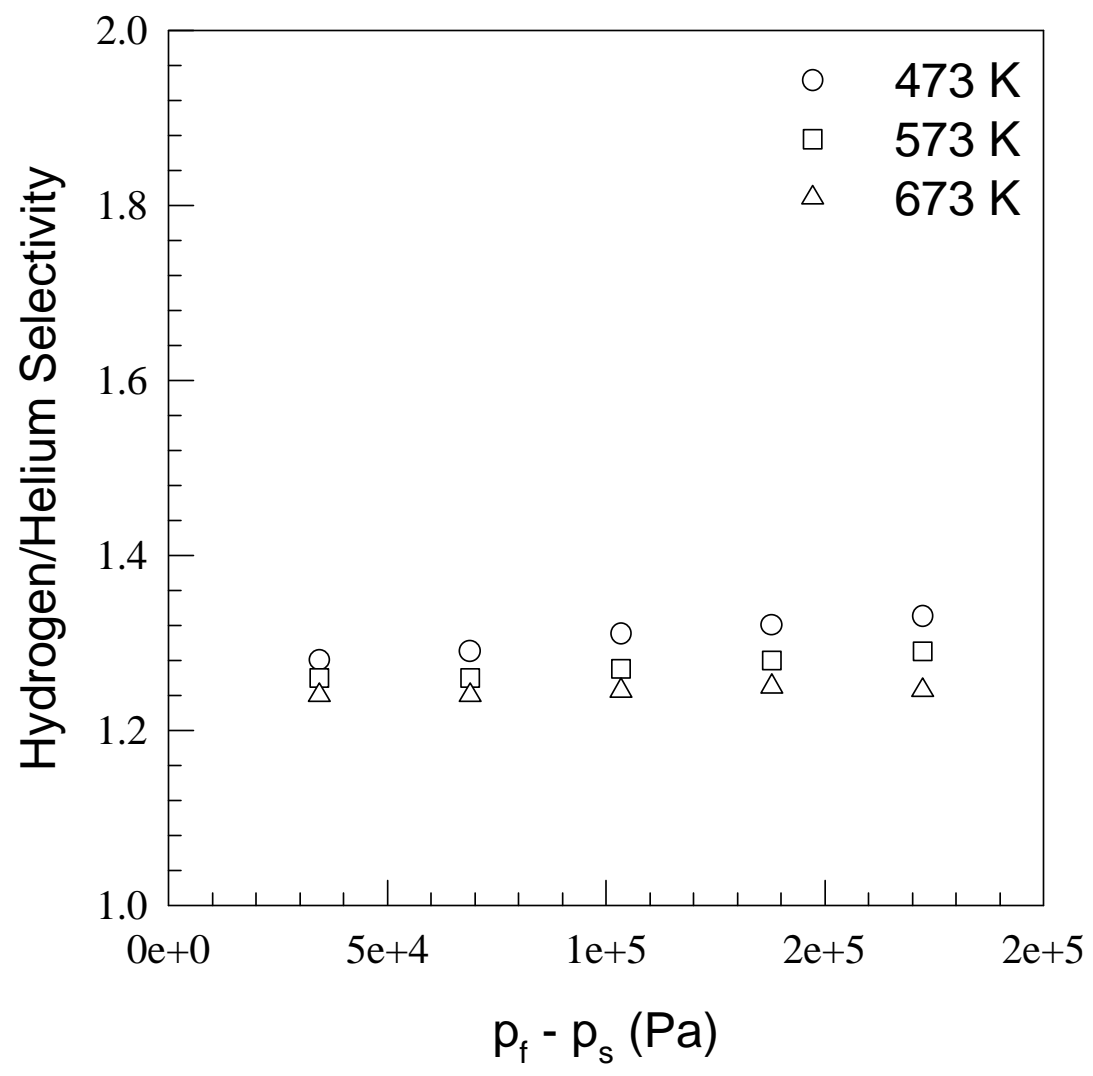

FIGURE 16: Effect of transmembrane pressure difference $\left[p_{H} \mathbf{g}-p_{H} \mathbf{g}\right.$ on hydrogen/argon selectivity at various temperatures for hydrogen selective ceramic membrane (commercial) for pure gases. 


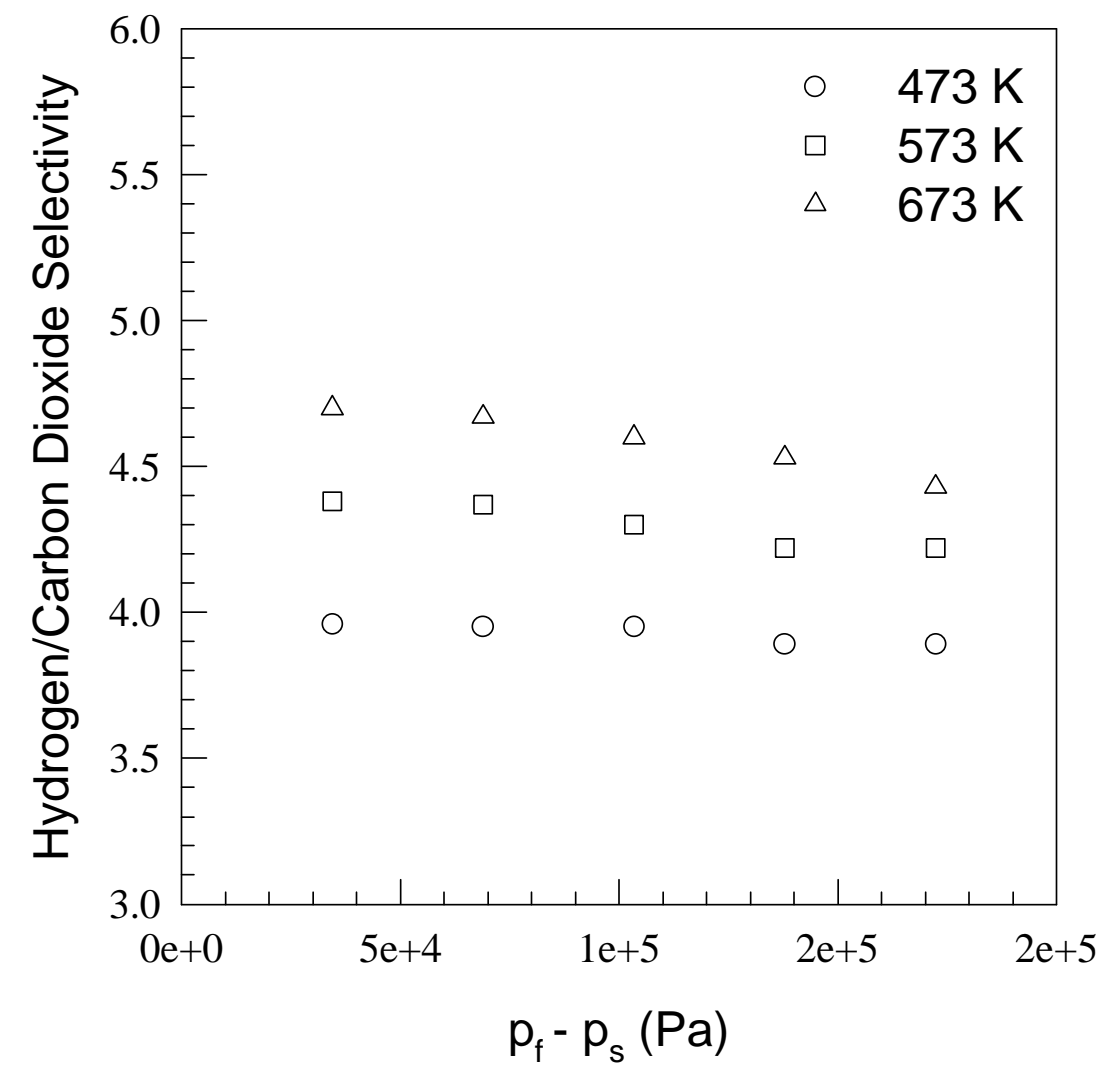

FIGURE 17: Effect of transmembrane pressure difference $\left[\boldsymbol{b}_{H} g-\boldsymbol{p}_{H} g\right]$ on hydrogen/carbon dioxide selectivity at various temperatures for hydrogen selective ceramic membrane (commercial) for pure gases. 


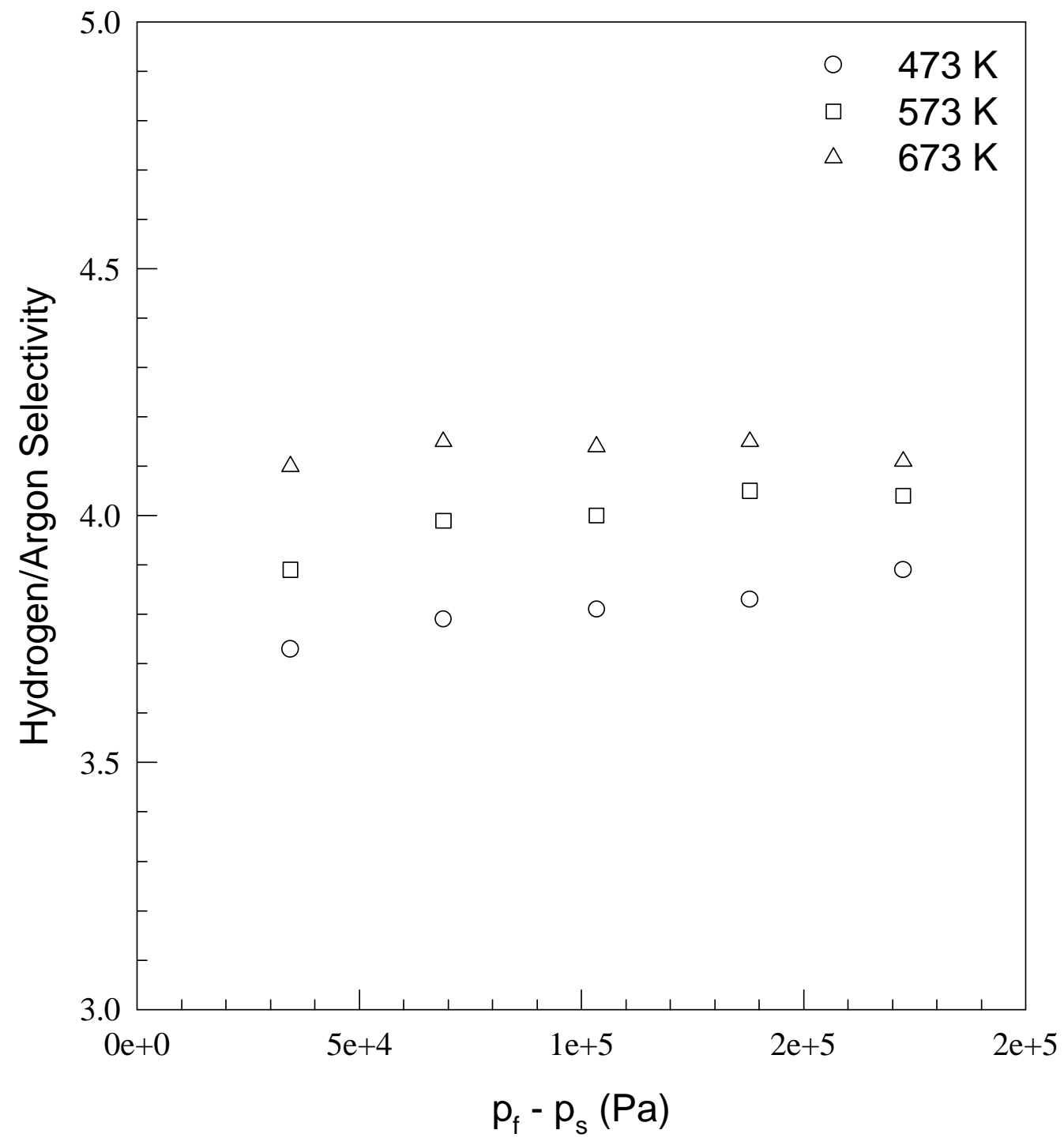

FIGURE 18: Effect of transmembrane pressure difference $\left[\boldsymbol{p}_{H} g-\boldsymbol{p}_{H} \mathbf{g}\right.$ on hydrogen/argon selectivity at various temperatures for hydrogen selective ceramic membrane (commercial) for pure gases. 


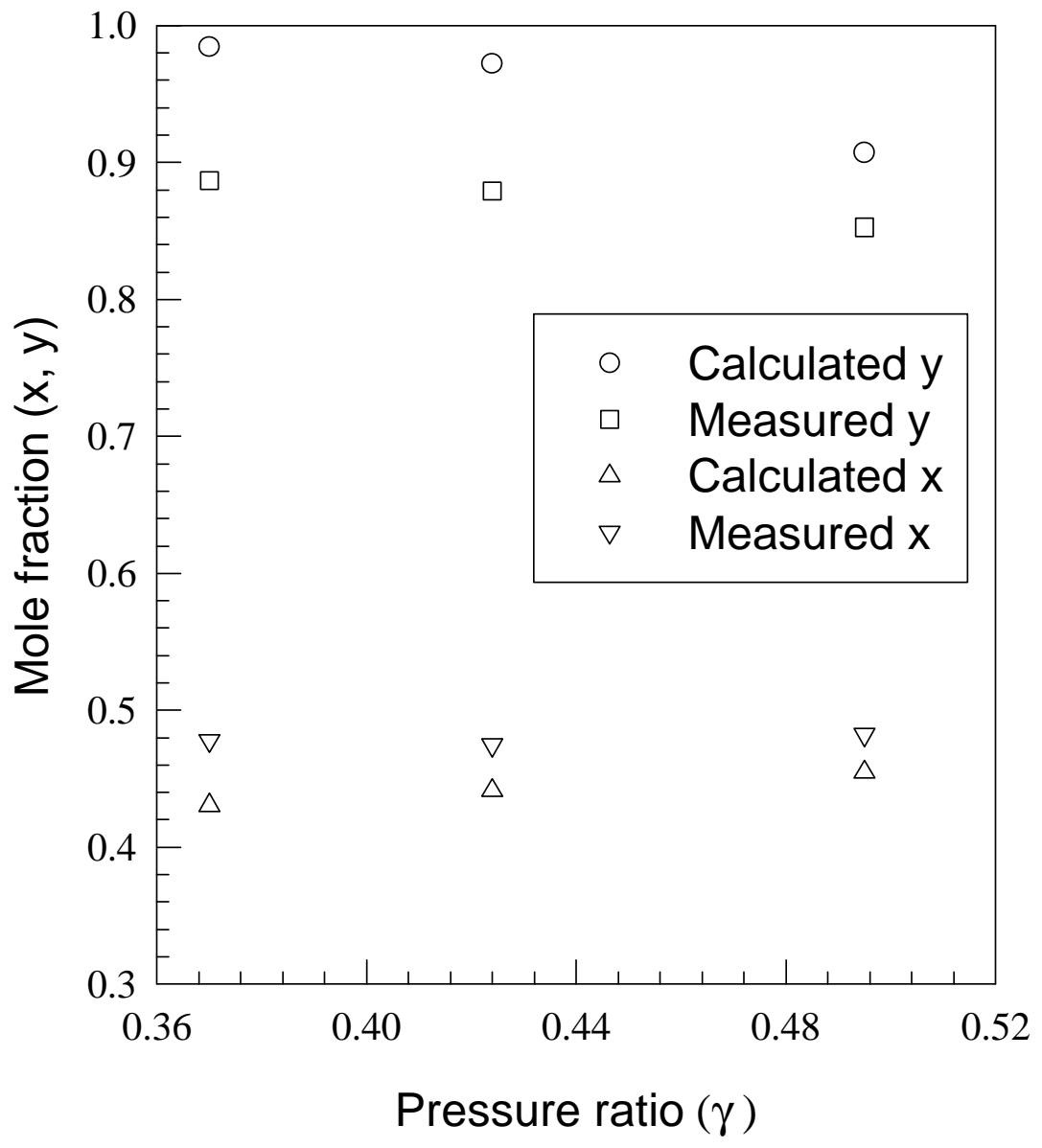

FIGURE 19: Effect of pressure ratio on permeate and reject compositions at $573 \mathrm{~K}$ compared to model preditions for palladium-ceramic composite membrane with $9.77 \mu \mathrm{m}$ film for cocurrent flow model. 


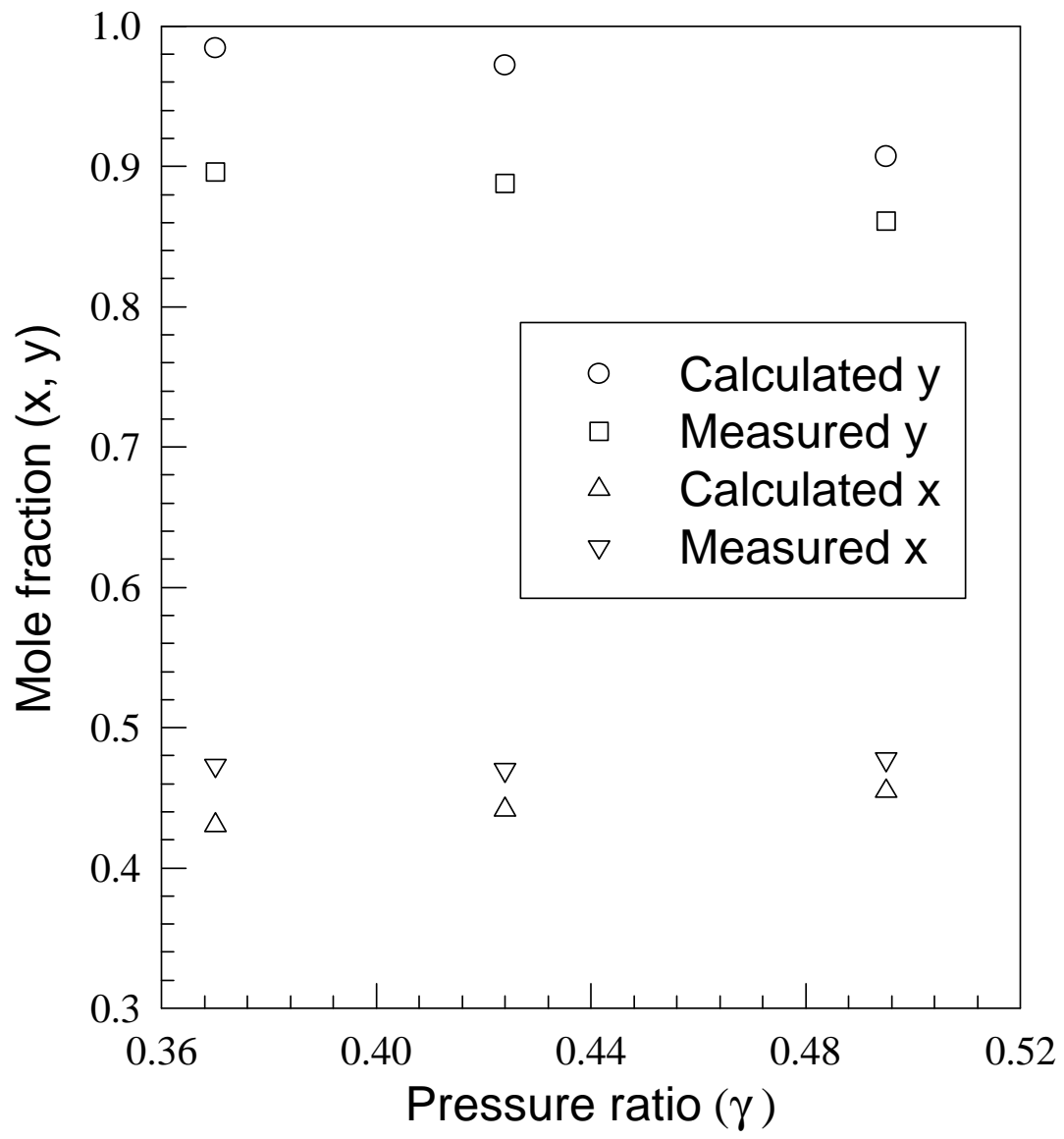

FIGURE 20: Effect of pressure ratio on permeate and reject compositions at $573 \mathrm{~K}$ compared to model preditions for palladium-ceramic composite membrane with $9.77 \mu \mathrm{m}$ film for cocurrent flow model. 